\title{
EMPRESARIOS ESPAÑOLES EN EL NORTE DE MÉXICO (1850-1912)
}

\author{
MARIO CERUTTI
}

Universidad Autónoma de Nuevo León

(Monterrey, México)

\section{RESUMEN}

En este trabajo se estudia el importante papel desempeñado por los empresarios españoles en la formación de la sociedad capitalista en el norte de México. La información que disponemos muestra la presencia de prominentes hombres de negocio de origen español al menos desde 1840. Aunque limitada en términos cuantitativos la inmigración española asumió en México durante la segunda parte del siglo xIX una importancia difícil de exagerar entre los grupos propietarios y empresariales.

\section{ABSTRACT}

This paper studies the significant role played by Spanish entrepreneurs in the formation of the capitalist society in Northen Mexico. The available information shows the present of prominent businessmen of Spanish origin from 1840 onwards. Although limited in cuantitative terms the Spanish emigration had an important impact on Mexico during the second part of the xxxth century.

\section{INTRODUCCIÓN}

El capital, las propiedades y las empresas manejadas por españoles parecen haber jugado un papel muy significativo en el ciclo formativo de la sociedad capitalista en México. Esta conclusión, algo inesperada pero consistente, deriva de los múltiples estudios sobre la historia económica y empresarial —en su mayoría de carácter regional - desarrollados en el 
país en los últimos años. Si bien se trata de una conclusión provisional, con mayor validez para el norte y el centro de México, sus datos insisten en que la presencia prominente de hombres de negocios de origen español fue una constante entre 1840 y la revolución que estalló en 1910 .

Aunque limitada en términos cuantitativos, la inmigración española asumió en México durante la segunda parte del XIX una importancia difícil de discutir entre los grupos propietarios y empresariales. Como lo ha destacado Clara Lida, disfrutó el perfil de inmigración privilegiada: se caracterizó por ser numéricamente débil, de «insignificancia cuantitativa», pero con un desmedido peso en «algún aspecto del mundo del capital, del poder, de la política, de la vida profesional (y) del empleo» ${ }^{2}$. Dentro de las actividades empresariales del México que corrió entre 1850 y 1910 , su impacto - tanto por su elevada proporción entre los nuevos sectores burgueses como por su ramificación geográfica - resultó decisivo, amplio y diverso ${ }^{2}$.

El reconocimiento de la crucial importancia de los empresarios y propietarios de origen hispano proviene, en buena medida, de lo que hemos preferido llamar investigación regional ${ }^{3}$. En México, su desarrollo -notorio desde fines de los setenta - brindó amplia acogida a la historia económica. Los trabajos sobre empresarios se multiplicaron en la medida que se incrementaba el estudio sobre las actividades económicas del siglo XIX, en que una gruesa porción se concentraba en la vida material de los diferentes espacios regionales, en que se atendía a quienes comandaban la minería, los ferrocarriles, el comercio, la agricultura, los bancos, los servicios o la industria fabril. La fusión entre historia económica e historia empresarial ${ }^{4}$,

${ }^{1}$ Lida $(1994$, p. 15-18) apunta que a fines del porfiriato (1876-1911) eran alrededor de 30.000 los españoles residentes en México, el 0,2 por 100 del total de la población en 1910. Si se compara con Argentina y Cuba se percibirá una abismal diferencia en cuanto a cantidad de inmigrantes e impacto en la estructura poblacional. Sobre Argentina véase Sánchez Alonso (1988 y 1992), y Cortés Conde (1988); sobre Cuba, Maluquer de Motes (1992).

${ }^{2}$ Cerutti (1995), passim.

${ }^{3}$ Desde mediados de los setenta comienza a proliferar en México la investigación histórica concentrada en espacios regionales específicos. La tendencia coincidió con uh notable incremento de los estudios sobre el siglo $\mathrm{xx}$, etapa caracterizada en numerosas sociedades latinoamericanas ( $\mathrm{y}$ no pocas europeas) por procesos políticos, militares, sociales y económicos de dimensiones e impacto regionales. La idea de una bistoria nacional única se mostraba poco eficaz para aclarar las intensas diferencias que mostraban las dinámicas regionales. La relación entre investigación regional y estudios empresariales en México ha sido tratada en Cerutti (1996a).

${ }^{4}$ Luciano Segreto (1994, p. 17) indica una fusión similar en España e Italia, aunque alude a la historia de la empresa en lugar de la historia de los empresarios. 
por tanto, es claramente perceptible en la historiografía regional mexicana, en especial la dedicada al período que aquí nos ocupa.

Uno de los sesgos más fructíferos de la historia económica y empresarial que ha operado con espacios regionales fue el seguimiento de los procesos formativos del capital y de la propiedad en el México decimonónico. El rastreo durante décadas de uno, dos o varios empresarios -0 de familias empresariales- arrojó una masa de información no sólo novedosa: también factible de generar conocimientos cotejables con los de otras sociedades latinoamericanas. Al efectuar este ejercicio comparativo buena parte de las suposiciones de un cuarto de siglo atrás - generadas por autores tan imbuidos en el combate ideológico como alérgicos a las labores empíricascomenzó a desdibujarse. Veamos algunos ejemplos.

1. El origen mercantil. Como muchos de los países latinoamericanos -y más de uno europeo- México transitó un siglo XIX poblado de crisis políticas, guerras internas e internacionales, debilidad institucional extrema, aislacionismos e influencias regionales y demás circunstancias que mucho tienen que ver con la configuración histórica del Estado-nación. Su devenir estuvo signado, además, por uno de los grandes dramas de la historia continental: la pérdida frente a Estados Unidos (1846/1847), de más de la mitad del territorio heredado de España. Este escenario global explica por qué los sectores burgueses más prominentes se desempeñaban sobre todo en el plano de la intermediación comercial y financiera. La transferencia masiva de capitales y de bienes a la producción — con los riesgos e incertidumbres consiguientes - no se iba a manifestar hasta que un nuevo orden jurídico, una relativa restabilidad sociopolítica y demandas regulares en los mercados internacional e interno se manifestaran con firmeza.

Lejos de apuntalar la idea de una actividad parasitaria, negadora de la actividad productiva, «históricamente conservadora» -como se solía indicar en aquellos años sesenta-, la investigación reciente ha reconocido el papel estratégico de estos agentes socioeconómicos en un triple sentido: a) en la acumulación de importantes capitales que - ya en los setenta y ochenta, tras las reformas liberales- promoverían otras actividades económicas; b) en el ejercicio de estratégicas funciones crediticias, al menos entre 1850 y $1900 ; c)$ en la adquisición de una experiencia empresarial que, sin duda, facilitó o encauzó el pasaje hacia otros quehaceres: industria fabril, bancos, agricultura especializada, ganadería, explotación forestal, 
minería, transportes, servicios. El papel del capital mercantil debió, por tanto, ser redimensionado ${ }^{5}$.

2. Crédito y bancos. Un énfasis particular hay que poner en el movimiento crediticio, semimonopolizado por casas mercantiles durante los últimos cincuenta años del siglo XIX. El papel de los comerciantes (sistemáticos prestamistas y gestores de otros servicios financieros) habría sido una de las claves de la reconstrucción económica que diferentes espacios regionales tuvieron que recorrer tras el ciclo de guerras interna e internacionales (1848-1867). Los casos de Yucatán y La Laguna -donde se registraron dos de los más llamativos ciclos de crecimiento agrícola a partir de 1870 parecen determinantes.

El arribo de los bancos, por su lado, perfiló dos fenómenos: a) un alto porcentaje de estas instituciones especializadas contó entre sus fundadores a muchos de los comerciantes/prestamistas que habían sobresalido en décadas anteriores; $b$ ) los bancos, ya en los noventa, no ocuparon -y quizá ni disminuyeron- el muy extenso nicho crediticio cubierto por las casas mercantiles o por prestamistas individuales.

3. Apropiación y uso de la tierra. Mientras eso ocurría, un apreciable porcentaje de capitales regionales fue utilizado en la adquisición de tierras rurales o urbanas. Los grupos burgueses enredados en el tráfico mercantil e instrumentadores del crédito se convirtieron - con expresiva frecuenciaen terratenientes. Las leyes liberales — tanto las de desamortización (de manera similar a España) como las de colonización- abrieron el camino para la apropiación del suelo y del agua en escala diversa. Esta transferencia de capitales de origen mercantil a la tierra resultó otro componente vertebral en la reactivación productiva que se observó desde mediados de los años setenta. Una buena porción de las tierras arrebatadas a la iglesia católica, los municipios y las comunidades indígenas, de las ganadas (en el norte) al desierto y a las culturas seminómadas, o en las poco accesibles laderas de las zonas montañosas fueron subordinadas al capital. Una ganadería más intensiva, el desenvolvimiento de la explotación forestal y una próspera

${ }^{5}$ El tipo de fuentes utilizado, el momento histórico elegido y la moderada amplitud del espacio indagado permitieron que estas investigaciones siguieran detalladamente -a veces en forma casi cotidiana- el itinerario que perfiló a buena parte del empresariado del México decimonónico. 
agricultura especializada poblaron la geografía de no pocos espacios regionales ${ }^{6}$.

4. Apellidos extranjeros, capitales regionales. En esta síntesis introductoria quisiéramos insistir en uno de los resultados más singulares de la investigación reciente: el relativo al origen regional, local, de muchos capitales que en la literatura de los años sesenta y setenta se consideraban extranjeros. Dentro de la limitada inmigración que México recibió en la segunda mitad del xxx, una porción considerable provenía de España (sobre todo del norte); arribaron asimismo ingleses, irlandeses, estadounidenses, franceses, italianos y alemanes. Al seguirse con minuciosidad los procesos formativos del capital se ha comprobado que no pocos de estos inmigrantes tuvieron éxito, que acumularon enormes fortunas y bienes. Pero también se ha verificado lo siguiente: a) que al llegar a México solían ser muy jóvenes y no disponían de mayores recursos; $b$ ) que el ciclo formativo de capitales y de experiencia empresarial suponía muchos años a veces décadas; c) que su manera de desempeñarse en el ámbito mercantil o de la producción no difería radicalmente del que mostraban sus colegas de origen mexicano.

La lista de casos analizados es lo suficientemente extensa para que se descarte ya, en la historiografía especializada, la habitual confusión entre apellidos extranjeros y capital extranjero. Por su historia - su nacimiento, crecimiento y reproducción en espacios geográficos definidos-, por su intensa inserción en la economía vernácula y por su ínfima o nula relación con la estructura capitalista de los países de origen de los inmigrados, no puede aplicarse a estos capitales el calificativo extranjeros.

Un quinto ejemplo para contrastar lo que se afirmaba un cuarto de siglo atrás podrían constituirlo los empresarios de raíces españolas. Aunque en este punto - muy ligado a los anteriores- deberíamos incluir en el cotejo a porciones de la historiografía española, remisa a aceptar que la España del xIX pudiese generar eso que llaman «espíritu empresarial». Veamos.

${ }^{6}$ Otras dos consecuencias del avance del capital sobre el suelo fueron: a) la multiplicación de un mercado urbano y rural de tierra, dato clave en la configuración del mercado interior; $b$ ) ya a fines del $\mathrm{xx}$ - con la normatividad porfiriana en pleno vigorla apropiación del suelo fue sobreestimulada por la posibilidad de monopolizar el subsuelo y su paralelo engarce con el desarrollo minero. 


\section{DE NORTE A NORTE (1850-1885)}

Rasgo común en muchos de los españoles estudiados fue - justamente- esa trayectoria comercial caracterizada por su perdurabilidad temporal, la magnitud que adoptó al menos desde los años sesenta del siglo XIX y su temprana relación con las actividades crediticias. Si el acercamiento a la propiedad o manejo de la tierra solía ser impactante, ha quedado en claro también que no pocos remataron su periplo mexicano con una sustancial inserción de bienes y caudales en la industria fabril, la minería, los transportes y los servicios en general.

Dos elementos que emergieron con regularidad en las trayectorias personales o familiares indagadas fueron citados ya al hablar de los inmigrantes en general, aunque entre los españoles era casi una constante: arribaban a México muy jóvenes y - tras su experiencia inicial en casas mercantiles de compatriotas - el proceso de construir la fortuna indiana era bastante prolongado. Finalmente, una alta proporción de inmigrantes provenían del norte peninsular: asturianos, vascos y santanderinos sumaron un porcentaje mayoritario dentro del universo analizado.

Si nos detenemos en el norte mexicano ${ }^{7}$ habría que reconocer de inmediato que ciudades como Monterrey y Chihuahua, puertos como Tampico, villas como las que rodeaban el río Bravo o espacios económicos que en la segunda mitad del XIX se encontraban en plena construcción -como la comarca lagunera - fueron centros fértiles de atracción para comerciantes y propietarios de raíces hispanas (mapa 1).

\section{Monterrey y el Bravo (1850-1870)}

La capital de estado de Nuevo León se tornó un excelente punto de referencia para analizar la prominencia que durante la segunda parte del XIX alcanzaron en el norte de México los empresarios de raíces penínsulares.

${ }^{7}$ La actividad mercantil se manifestó en forma singularmente intensa en el norte oriental de México - debajo del estado de Texas tras el cambio de la línea divisoria con Estados Unidos, en 1848. La flamante frontera del Bravo brindaría oportunidades espectaculares de enriquecimiento a comerciantes y casas intermediarias ubicadas en ambos lados del río, tanto en tiempos de guerra como en épocas de paz. Se inauguró entonces una relación tan cotidiana con la economía de los Estados Unidos —el más grande mercado nacional creado por el capitalismo- que no pudo dejar de contextualizar el desenvolvimiento de poderosos grupos empresariales. Este escenario de oportunidades incluyó, por supuesto, a los inmigrantes españoles. 


\section{MAPA 1}

El norte de México: referencias básicas y comarca lagunera

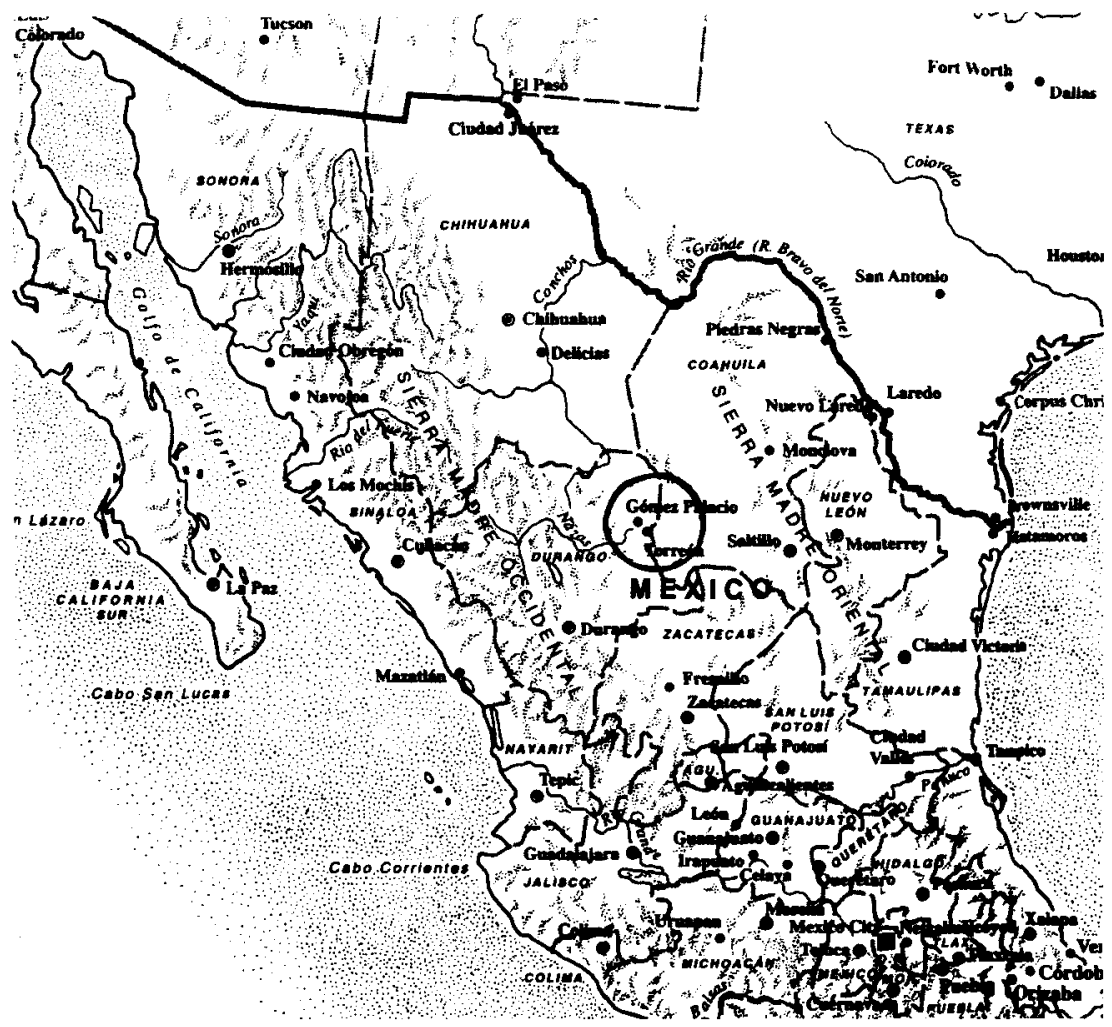

Por cuatro razones: a) desde esta ciudad, asturianos, santanderinos y vascos protagonizaron un exitoso devenir mercantil y financiero; $b$ ) una notoria porción de esos comerciantes contribuyó a sentar las bases del desarrollo industrial que Monterrey transitó a partir de $1890 ; c)$ redes comerciales y proyectos comunes los vincularon con una gruesa porción de la economía norteña (lo que hizo posible indagar a otros compatriotas que operaban en el gran septentrión mexicano); d) desde Monterrey salió una considerable porción de los capitales que impulsaron el florecimiento agroindustrial y financiero de la Laguna, comarca de agricultura especializada a la que se dedicará amplio espacio en este trabajo.

En dos palabras: la historia económica y empresarial de Monterrey entre 1850 y la Revolución no resultaría cabalmente comprensible sin tener 
en cuenta las actividades conducidas por españoles. Su protagonismo - imbricado con el de otros inmigrantes y con el de poderosas familias mexicanas- es fuertemente representativo del comportamiento más general de los sectores empresariales que actuaban en el dinámico norte mexicano.

Fundadores de poderosos grupos empresariales regiomontanos fueron el asturiano Valentín Rivero y Álvarez Jove y los vasco/santanderinos hermanos Hernández. Llegaron muy temprano a Monterrey y crecieron estrechamente vinculados con prósperos hispanos asentados en la línea del Bravo. Entre estos últimos sobresalió un racimo de vascos: José San Román, su asociado y discípulo Francisco Armendaiz y los hermanos Maiz (primos de Armendaiz).

Tanto Rivero como los Hernández emigraron a México con recursos limitados. Biógrafos familiares recuerdan que sus respectivos acercamientos a América coincidieron con su incorporación a casas mercantiles ya montadas, donde fueron admitidos como empleados.

Valentín Rivero —oriundo de Gijón — abordó Monterrey cuando sumaba veintiún años: en 1837 fue acogido por el comerciante santanderino Juan Francisco de la Penilla, primer vicecónsul de España en la ciudad tras el restablecimiento de las relaciones diplomáticas entre ambos países. Seis años después, en 1843, instaló su propio negocio: Valentín Rivero y Cía. Como sucedió con Mariano Hernández, Pedro Calderón y José Morell, Rivero era un reconocido comerciante ya a mediados de los cincuenta. El cambio de la línea fronteriza - tras la guerra con Estados Unidos- comenzaba a impactar sobre Monterrey, ciudad que al recrudecer los conflictos entre liberales y conservadores asumió una evidente importancia militar, política, administrativa y comercial.

Durante la década de 1850 se afianzó en Monterrey, asimismo, Mariano Hernández y Luengas, originario de Villaverde de Trucíos. Había arribado alrededor de 1850 tras pasar por La Habana y, fugazmente, por Nueva Orleáns. De 1852 datan las primeras referencias de su inicial significación mercantil. En 1854, junto con el mismo Rivero y otros dos españoles destacados - Pedro Calderón y José Morell- contribuyó a poner en marcha la primera fábrica textil moderna del estado: La Fama de Nuevo León, en la que simultáneamente participó uno de los grandes comerciantes mexicanos, Gregorio Zambrano.

Mariano anunció en enero de 1855 la apertura oficial de una casa que - sucesivamente reorganizada - perduró hasta mediados del actual siglo. Una de las modificaciones más duraderas, su conversión en la razón Hernández Hermanos y Cía., en 1861, supuso la integración de su hermano 
Estanislao, quien quedó a cargo de la casa comercial de manera efectiva cuando Mariano se marchó a Bilbao, poco antes de 1865. Tras Estanislao llegaron José María y Ángel Hernández, que hicieron operar sucursales en Matamoros, Brownsville y - hacia los setenta - en Villa Lerdo ${ }^{8}$.

Aunque Rivero, Hernández y otros colegas de Monterrey intervinieron con amplitud en el financiamiento de guerra para el Ejército del Norte, que desde 1855 comandó el gobernador de Nuevo León, Santiago Vidaurri, es evidente que hasta 1870 el gran comercio presidió su actividad económica. Algo similar ocurría con los vascos José San Román y Francisco Armendaiz, quienes en esas mismas décadas se enriquecían en la boca del río Bravo. Una coyuntura particular lo favorecía: la guerra civil (de Secesión) en los Estados Unidos, que desató una prosperidad explosiva por estos aislados desiertos del norte.

\section{Guerra en Estados Unidos, euforia en el noreste}

Desde mediados de los años cincuenta y hasta fines de la década siguiente un fenómeno central enmarcó el funcionamiento de la flamante línea fronteriza diseñada por el río Bravo: la guerra. A uno y otro lado de su cauce se vivieron con rudeza los conflictos internos e internacionales que sacudían ambas sociedades.

El plan de Ayutla abrió en México un período de choques militares que arreció desde 1858 por las luchas de Reforma y a partir de 1862 por la intervención francesa. En Estados Unidos entre 1861 y 1865 estalló la guerra de Secesión, motivada por la decisión de los plantadores del Sur esclavista de separarse del tronco nacional.

Aunque las operaciones militares cubrieron buena parte de los respectivos territorios, en torno al Bravo se vivió una situación diferencial: su condición de división internacional auspició un enorme tráfico destinado a los imperativos bélicos. Los flujos mercantiles alcanzaron su máximo vigor entre 1861 y 1865 , cuando el Bravo quedó singularmente conectado con las economías industrializadas del mundo atlántico. Durante la guerra de Secesión, el extremo meridional de Texas y el noreste mexicano se convirtieron en la salida menos riesgosa para que el algodón del sur llegara a los ávidos mercados de la revolución industrial. Sus imperiosas demandas activaron un gigantesco tráfico en los desiertos que bajaban de la porción superior de Texas hasta Monterrey, desde Matamoros hasta Piedras Negras.

\footnotetext{
${ }^{8}$ Las referencias documentales pueden encontrarse en Cerutti (1995), pp. 18-31.
} 
El algodón se transformó con rapidez en la moneda de pago de los rebeldes sureños, cuyos ejércitos requerían todo tipo de abastecimientos. Matamoros, en la boca del Bravo y pegado a Texas, vivió horas irrepetibles gracias al bloqueo que soportaban puertos como Nueva Orleáns, Mobile y Galveston. El cierre de Nueva Orleáns hizo de La Habana otra de las grandes estaciones del algodón. Desde Cuba, como puede suponerse, los intermediarios de origen peninsular jugaron un papel privilegiado en los circuitos de abastecimiento al sur, función completada con presteza por compatriotas que habitaban el noreste mexicano ${ }^{9}$.

\section{Entre la Sierra Madre y La Habana}

Puede ser muy ilustrativo reseñar las actividades que en estos tiempos desempeñó el vasco José San Román y Palacio. Residente en Matamoros y Brownsville, su quehacer destacó no sólo por un impresionante aprovechamiento del auge del algodón: también por su estratégica conexión con otros españoles en la misma línea del Bravo, en Monterrey y en La Habana.

Nacido en las cercanías de Bilbao, San Román se instaló en Matamoros en 1846 tras una breve estancia en Nueva Orleáns. De 1852 provienen las primeras referencias de sus contactos con compatriotas de Monterrey. $\mathrm{Y}$ es a comienzos de los sesenta cuando acoge en el Bravo a otro vasco y pariente: Francisco Armendaiz y Arsuaga. San Román se convirtió en uno de los grandes conductos para la salida del algodón hacia la economía atlántica al colocar con fluidez la fibra en puertos como Nueva York, la misma Habana, Burdeos, Liverpool, Barcelona. Más aún: podía localizar en esos mismos lugares y en el norte de México muchas de las provisiones que necesitaban los confederados en general y el propio Texas en particular. Su función resultó análoga a la de otros destacados probombres del tráfico del algodón: Miffin Kennedy, Richard King y Charles Stillman del lado norte del Bravo; Evaristo Madero y Patricio Milmo, al sur del río.

No debe olvidarse que una de las tareas primordiales de este vasco era servir de intermediario -importador y exportador- en el gran norte centro/oriental de México, labor eslabonada hacia y desde el interior mexicano por un grueso racimo de colegas. Sus contactos se ramificaban con

9 Referencias para estos acontecimientos en Cowling (1926), Delaney (1955), Diamond (1940), Graf (1942), Irby (1969), Mayer (1976), Owsley (1931), Tyler (1973), Cerutti (1994a y 1996b). 
mercaderes y casas comerciales de Tamaulipas, Coahuila, Nuevo León, Zacatecas, Durango, San Luis Potosí y Chihuahua. Era a través de San Román que se exportaban grandes cantidades de cobre, plomo, lana, pelo, y pieles de chivo, cabra y vacunos.

La documentación consultada ${ }^{10}$ constató a la vez el amplio peso del metálico en el conjunto de las exportaciones. La plata mexicana era un lubricante imprescindible para aceitar los lazos mercantiles con el exterior: muy apreciada en Estados Unidos y en los medios europeos, constituía además una de las claves de la circulación en el Golfo de México. Dado que Monterrey y sus ya afianzados comerciantes se distinguían como ejes de una geografía regional hilvanada con mercancías y plata, se multiplicaron los lazos entre San Román, su asociado Armendaiz y sus coterráneos Rivero y Hernández (mientras los hermanos Hernández mostraban un alto grado de participación en las remesas de lana y cueros; Rivero solía encargarse de colectar plomo y cobre en cantidades significativas).

Desde 1862, empero, comenzó a tomar una abrumadora importancia el algodón. Ya en 1863 los envíos de la fibra que descendía de los Estados Unidos saturan los registros. Decenas de miles de pacas fueron embarcadas en Matamoros por gestión directa o con asesoramiento del vasco San Román. Y La Habana sobresalía como el más impresionante escalón hacia la economía atlántica. Eslabón entre el Bravo, Nueva York y los principales puertos europeos, la capital isleña operaba como un corazón que bombeaba toneladas de algodón, plata y abastecimientos desde y para el sur confederado ${ }^{11}$. La Habana resaltaba asimismo por la dinámica que asumieron en este ciclo los comerciantes de nacionalidad española. San Román, parece obvio, era su representante dilecto en tierras mexotexanas, a quien se le confiaban negocios importantes y de quien se contaba con las máximas garantías para inversiones en el tráfico de algodón.

En síntesis, el vasco José San Román y Palacio fue uno de los grandes agentes mercantiles de la coyuntura bélica. Desde el punto de vista de la historia económica y empresarial, su caso resultó un excelente objeto de estudio para observar el comportamiento de una firma comercial ante situaciones tan diversas y cambiantes: $a$ ) por su manera de actuar y adaptarse en tiempos de guerra; $b$ ) por su capacidad de operar en un ámbito económico binacional cruzado por el río Bravo; $c$ ) por su conexión directa con un espacio mercantil de alta complejidad e importancia, como era

${ }^{10}$ San Roman Collection, Barker Texas History Center (BTHC, Universidad de Texas en Austin).

"San Román Collection, 1862-1865. 
el configurado por el Golfo de México; d) por el aprovechamiento de su condición de español para trabajar con ese nudo del Golfo que era La Habana; e) por sus redes hacia el norte mexicano, trama que sobre todo ejercía con compatriotas; $f$ ) por su telaraña de vínculos hacia Texas, último peldaño estadounidense del algodón y receptor final de los abastecimientos de guerra; $g$ ) por su eficacia para encadenar las demandas de guerra, los puertos mexicanos y La Habana con puntos relevantes del espacio atlántico: Nueva York, Liverpool, Londres, Manchester, El Havre, París, Barcelona ${ }^{12}$.

\section{Posguerras y reconstrucción}

Casi todas las funciones cumplidas por estos comerciantes hasta mediados de los sesenta seguían cumpliéndose una década después. Si seguimos la pista de San Román, verbigracia, se observa que continuaba operando desde Matamoros con pieles, lana y plata en abundantes cantidades. Los vínculos con comerciantes y firmas del norte se mantenían con vigor (cuadro 1). Los lazos con el mundo atlántico perduraban (cuadro 2), aunque más ramificados que en tiempos de la Civil War. La llegada del telégrafo y —en el sur de Texas - del ferrocarril había agilizado las comunicaciones, mejorado la información y acentuado muchos de estos vínculos.

Pero se contabilizaban algunas novedades. La primera y más obvia era que el algodón había abandonado al sur texano y el noreste de México. Este rincón del Golfo, por tanto, dejó de ser uno de los pivotes en la enorme cadena del comercio atlántico. La luego añorada era de los algodones había terminado. Como Nueva Orleáns había recuperado su importancia, La Habana y sus españoles retornaron a la posición relativamente secundaria mantenida hasta 1860 .

En segundo lugar ambas economías - la estadounidense y la mexicana- recorrían la reconstrucción de sus respectivas posguerras. Y si Texas se recuperaba con la mirada puesta en las múltiples demandas del vigoroso mercado nacional estadounidense, algo similar ocurría con el norte de México: una lenta pero firme actividad productiva se ramificaba desde el río Bravo hacia el sur, avivada sobre todo por las demandas de la economía vecina que - con dinamismos insospechados- corría hacia la segunda revolución industrial.

\footnotetext{
${ }^{12}$ Cerutti (1994a y 1996b).
} 


\section{CUADRO 1}

Comerciantes y firmas en México que operaban con San Román, 1875

\begin{tabular}{|c|c|c|}
\hline Casa o comerciante & Lugar & Estado \\
\hline R. Lajous ..... & Saltillo/Parras & Coahuila \\
\hline F. Lierret.. & Mier & Tamaulipas \\
\hline Salvador Jarrié.... & Monterrey & Nuevo León \\
\hline Juan Decker.. & Camargo & Tamaulipas \\
\hline Laffargue y Lacaze..... & Camargo & Tamaulipas \\
\hline Pío Bermejillo y Cía............................... & México DF & \\
\hline Gabriel San Román.... & Zacatecas & Zacatecas \\
\hline Hernández Hnos. Suces..... & Monterrey & Nuevo León \\
\hline Ramón Cruz Ortiz .................. & Zacatecas & Zacatecas \\
\hline Valentín Rivero y Cía.... & Monterrey & Nuevo León \\
\hline Matías Hernández Soberón.. & San Luis Potosí & San Luis Potosí \\
\hline Diego de la Lastra y Cía. ........................ & Tampico & Tamaulipas \\
\hline Santos de la Maza....................... & Mineral de Catorce & San Luis Potosí \\
\hline Viuda de Larrache y Cía. ....................... & San Luis Potosí & San Luis Potosí \\
\hline A. Lagrange y Hnos. . & Monterrey & Nuevo León \\
\hline Ignacio García .......... & Mier & Tamaulipas \\
\hline 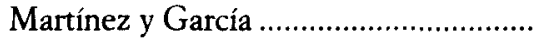 & Mier & Tamaulipas \\
\hline 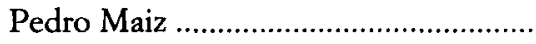 & Monterrey & Nuevo León \\
\hline Gómez Velasco, Martínez y Cía. ........... & Veracruz & Veracruz \\
\hline Francisco de la Fuente........................... & Linares & Nuevo León \\
\hline A. Duclós ... & Monterrey & Nuevo León \\
\hline Sota y Bolado......... & Saltillo & Coahuila \\
\hline José Calderón...... & Monterrey & Nuevo León \\
\hline 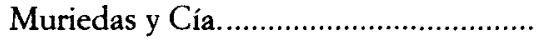 & San Luis Potosí & San Luis Potosí \\
\hline I.uis G. Coindreau ................. & Monterrey & Nuevo León \\
\hline Charles Mayer.......... & Mier & Tamaulipas \\
\hline Pedro Erquicia ........... & Parral & Coahuila \\
\hline C. A. Martínez y Cía.. & Veracruz & Veracruz \\
\hline Juan José Viña..... & Tampico & Tamaulipas \\
\hline Villanueva Hnos.... & Zacatecas & Zacatecas \\
\hline Trápaga y Cía............. & Tampico & Tamaulipas \\
\hline Santos Mora & Cadereyta Jiménez & Nuevo León \\
\hline Juan B. Mears ..... & Monterrey & Nuevo León \\
\hline 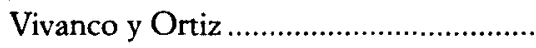 & San Luis Potosí & San Luis Potosí \\
\hline
\end{tabular}

FUENTES: BTHC, San Roman Collection, 1875. 


\section{CUADRO 2}

San Román: Contactos comerciales externos a México, 1875

\begin{tabular}{|c|c|}
\hline Firma o comerciante & Lugar \\
\hline Rousseau Olivier Co. & París \\
\hline Theo Hermann Co. & Nueva York \\
\hline Batchelor et Co..... & Havre \\
\hline San Antonio National Bank & San Antonio \\
\hline Ball, Hutching Co. ................. & Galveston \\
\hline M. Echeverría y Ca. & Nueva York \\
\hline Antonio Palacio ........ & Nueva Orleáns \\
\hline B. Bentegeat ........... & Bordeaux \\
\hline A. Baldwin Co. . & Nueva Orleáns \\
\hline Louisiana National Bank. & Nueva Orleáns \\
\hline F. Masich ...................... & Nueva Orleáns \\
\hline S. Hernsheim and Bro... & Nueva Orleáns \\
\hline Juan Marroquín ............. & Bilbao \\
\hline Galainena y Armendaiz & Burdeos \\
\hline Joseph Railton and Son. & Manchester \\
\hline J. Martinaud .................. & Burdeos \\
\hline Gassol Avendaño y Ca. & La Habana \\
\hline Del Valle Roe and Co... & Londres \\
\hline C. de Murrieta. & Londres \\
\hline Staver, Zigomala and Co.. & Manchester \\
\hline Sieg and Krug ..................... & Nueva Orleáns \\
\hline H. E. Woodhouse. & Brownsville \\
\hline H. Chamberlain Jr. & Rio Grande City \\
\hline Blas de Saràstegui.. & Bilbao \\
\hline Francisco de Saràstegui ............. & Nueva Orleáns \\
\hline 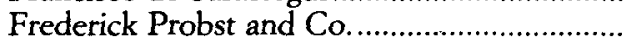 & Nueva York \\
\hline J. et J. Prom et Cie........... & Bordeaux \\
\hline Avendaño Hnos.. & Nueva Orleáns \\
\hline 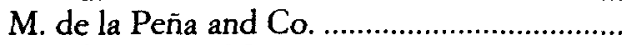 & Brownsville \\
\hline 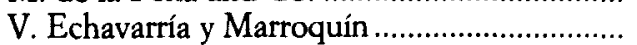 & Bilbao \\
\hline 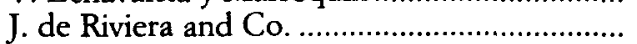 & Nueva York \\
\hline Wheelock, Finlay and Co............................... & Nueva Orleáns \\
\hline 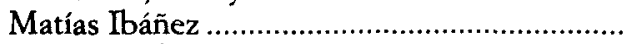 & Santander \\
\hline Francisco Ibáñez...... & La Habana \\
\hline Juan Traitè y Ca.. & La Habana \\
\hline Bennet and Thornton. & San Antonio \\
\hline Marks Hnos. y Cía. ............................................ & Nueva Orleáns \\
\hline Schuster, Fulda and Co.................................... & Manchester \\
\hline Jiménez and Son & Londres \\
\hline 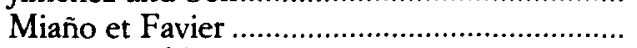 & París \\
\hline 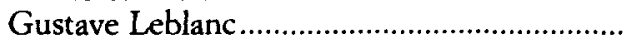 & París \\
\hline
\end{tabular}

FueNTES: BTHC, San Romar Collection. 
Fue en esos años setenta que - mientras San Román adiestraba a sus sobrinos y preparaba su atildado retorno al País Vasco- comenzó a destacar en la frontera Francisco Armendaiz y Arsuaga. A su lado crecieron los Maiz Arsuaga, grupo de cinco hermanos que, como los demás, iniciaron en el comercio su carrera empresarial. Natural de Arcentales (1833, en Vizcaya), Armendaiz era hijo de Miguel Armendáriz Maiz y Florentina de Arsuaga y Asemendi. El apellido Armendáriz se transformó en Armendaiz - segun cuenta uno de sus descendientes_- ${ }^{13}$ debido «al error del párroco de la capilla de San Pedro de la Mollineda», en Santander, donde fue bautizado Francisco. En cuanto a su hermano menor, Eugenio (lo acompañó durante años en la frontera), en los registros notariales vascos ${ }^{14} \mathrm{se}$ lo menciona como oriundo de Somorrostro, en la misma Vizcaya.

Si las primeras referencias sobre Francisco lo vincularon a San Román y al tráfico de algodón (1862 en adelante), es evidente que en los setenta su accionar se tornó más autónomo. La correspondencia de mediados de esta década lo muestra como un verdadero jefe de operaciones, dispuesto a abrir casas comerciales en diversos puntos del Bravo y negociar con las áreas del México central. Hacia 1875 estaba involucrado tanto con The Río Grande Railroad, Co., que recorría los tramos más mercantilizados del sureste texano, como en inversiones en la mina Refugio del Oro, situada en Zacatecas. En 1878 funcionaba bajo su dirección la casa Francisco Armendaiz Sucesores, siempre en Matamoros. Sostenía entonces una estrecha relación con sus primos Pedro y Ángel Maiz, con quienes se asoció en repetidas ocasiones antes de marcharse hacia Monterrey ${ }^{15}$.

${ }^{13}$ Joaquín de Armendaiz Noriega, comunicación personal, Madrid, 20 de setiembre de 1996.

${ }^{14}$ Archivo Histórico Provincial de Vizcaya (AHPV, Bilbao), protocolo de Calisto Ansuátegui, mayo de 1885 , fs. $1236-40 \mathrm{v}$.

15 Una síntesis de la información sobre este grupo de vascos puede incluir lo siguiente: 1) Hacia 1880, Armendaiz era propietario de dos casas mercantiles. Una operaba en Matamoros, la otra en Monterrey. En ambas estaba aliado con Pedro y Ángel Maiz. Fueron liquidadas a fines de aquel año. 2) Se ha podido confirmar que los Maiz se encontraban en el norte -Matamoros y Monterrey- ya en los setenta. Pedro Maiz trabajaba en México al menos desde 1876. A su hermano Angel se le detecta en 1878 en Matamoros. 3) Mientras en 1882 funcionaba en Monterrey la firma Pedro Maiz y Cía., los Maiz estaban asociados a su primo en la firma Armendaiz y Maiz Hnos., de Nuevo Laredo (disuelta en 1886). 4) Cuando en 1887 constituyeron la sociedad Pedro Maiz y Cía., seguramente continuadora de la establecida en 1882, quedaron incorporados seis hermanos: Justo, Joaquín, Agustín, José, Pedro y Ángel. 5) Mientras tanto, en 1883, una circular de Armendaiz comunicaba que había establecido una nueva casa en Nuevo Laredo, 220 kilómetros al norte de Monterrey y al sur de la no menos dinámica San Antonio. Un año antes había llegado el ferrocarril. 6) La circular agregaba que Armendaiz, en ese momento, contaba con otra sucursal fronteriza: 
El asturiano Valentín Rivero mostraba en los setenta, por su lado, una ascendente conexión con sectores productivos. Mientras la Fábrica de Hilados y Tejidos La Fama de Nuevo León continuaba en operaciones, se asoció en 1871 con los poderosos Zambrano (mexicanos) para fundar la Fábrica de Tejidos El Porvenir. En 1876 recibió —como pago de diversos préstamos- el molino El Hércules. Sus hijos Valentín y Ramón Rivero y Gajá (este último ingeniero graduado en París) se incorporaron paulatinamente a una actividad empresarial cada vez más compleja y diversificada. El gran comercio, empero, seguía predominando. A su lado, sin embargo, había fructificado un quehacer estratégico: el préstamo. Así pues, muchos de estos mercaderes se lanzaron a desempeñar el papel de financistas del flamante orden liberal.

\section{Gran comercio, crédito y actividades productivas}

Fue en esos años setenta cuando -en diversas regiones de Méxicoel capital mercantil tuvo que satisfacer el objetivo de aceitar y financiar el nuevo orden. La ausencia de un sistema bancario -que no habría de implementarse de manera firme hasta mediados de los noventa- colocó a los comerciantes en el núcleo de las fuerzas que impulsaban la economía mexicana. Las actividades prebancarias -depósitos, giros, créditos, descuentos, pagos al exterior - eran concretadas en proporciones casi absolutas por casas mercantiles.

En Monterrey y su espacio aledaño la actividad crediticia entre 1855 y la expulsión de las tropas francesas se había concentrado en los préstamos de guerra (destinados a mantener en pie alguno de los ejércitos en conflicto). Los comerciantes hispanos de Monterrey, verbigracia, tuvieron una amplísima participación. Pero el tipo de crédito que se requirió desde finales de los sesenta indicaba que algunas regiones del norte comenzaban a mostrarse aptas para movilizar diversos sectores productivos. La aventura prestamista que arrancó en los setenta no sólo reforzaba las antiguas funciones de intermediación mercantil: abría también el camino hacia la apropiación

operaba en Mier, poblado intermedio entre Nuevo Laredo y Matamoros. La mayoría de estas casas laboraba bajo el nornbre La India. 7) En 1886, poco antes de que los registros notariales informaran que Armendaiz vivía en Monterrey, sumó a su red de sucursales la inaugurada en Paso del Norte (Chihuahua). Como en todas las demás, el encargado era español. La referencia documental en Cerutti (1995), pp. $31-32$ y 58.59. 
o manejo de la tierra rural y urbana y alentaba la reconstrucción económica tras décadas de conflictos civiles e internacionales ${ }^{16}$.

Los movimientos financieros resultaban tan complementarios de la gestión comercial que varias casas de Monterrey habrían de caracterizarse, desde estos años, por la instrumentación de mecanismos próximos a los de un sistema bancario. Se convirtieron, además, en puente para las transacciones con el exterior ${ }^{17}$. La documentación auscultada ${ }^{18}$ brinda un panorama bastante claro de las conexiones que se establecieron entre grandes comerciantes y productores rurales, muy especialmente con agricultores. Observando estos movimientos desde la siempre activa Monterrey o desde villas y ciudades como Matamoros, Lerdo, Chihuahua, Saltillo y Durango destacan dos matices: a) la notoria presencia de nuestros españoles: San Román, Rivero, Armendaiz, los Maiz y la casa Hernández tuvieron un notorio desempeño como portadores de crédito; b) la combinación españoles/comercio/finanzas contó con un escenario predilecto en el ancho mundo del norte: la comarca lagunera.

\section{Españoles en la Laguna}

Desde principios de los setenta se estableció una progresiva conexión con la incipiente comarca de la Laguna (ubicada entre los estados de Coahuila y Durango, mapa 1), donde empezaba a generalizarse el cultivo del algodón. Su producción, destinada al mercado interior, fue acicateada por la gigantesca crisis que la guerra de Secesión descargó sobre los plantadores

${ }^{16}$ La acción del crédito durante los setenta y los ochenta sugiere que se afirmaban condiciones más estables en el crónicamente tumultuoso escenario vernáculo. La aplicación efectiva de la normatividad liberal y una progresiva estabilidad sociopolítica servían de estímulo y garantía a los dueños del capital. Las reformas liberales completaron en México el ciclo de laicización del crédito, el cual, en tiempos coloniales, había estado en considerable medida en manos de la iglesia católica. Si bien a fines del xvur y durante la primera mitad del XIX se acentuó la intervención de los comerciantes, el golpe final llegó con la nacionalización de los bienes del clero, consumada por Benito Juárez durante las luchas de Reforma. El capital mercantil manejó el crédito interno entre 1860 y mediados de los noventa, momento en que se afianza una red de bancos provinciales. La investigación regional ha mostrado largamente este proceso. Un estado de la cuestión en Cerutti (1992a).

${ }^{17}$ De la firma Hernández Hnos. se ha recordado: «En tiempos que las organizaciones bancarias no operaban por estas regiones se ocupó la casa de estas actividades, atendiendo el préstamo a plazo fijo o en cuenta corriente, descuentos y cambios sobre ciertas plazas de los Estados Unidos, Inglaterra, España, Francia y Alemania. Aún después de establecidos aquí los bancos locales continuamos sirviendo nuestras propias necesidades de importación y exportación». Hernández Mendirichaga (1945, p. 5).

${ }^{18}$ En general, libros de notarios. 
de la Confederación y - bueno es puntualizarlo- por una industria textil que en México se preparaba para el auge de los ochenta.

La agricultura especializada del algodón alteró de manera radical el desértico paisaje que hasta poco atrás habían recorrido los grupos apaches. En un cuarto de siglo la zona bañada por los ríos Aguanaval y Nazas pasó de ser un área marginal — bajo dominio de culturas seminómadasa manifestarse como escenario privilegiado de una intensa actividad productiva ${ }^{19}$. Para que la Laguna se transformara en la proveedora del 75 por 100 del algodón que a fines de siglo se consumía en México fue menester, previamente, encauzar y redistribuir las aguas que bajaban estacionalmente de la Sierra Madre Occidental. Esa tarea coincidió con un ágil proceso de transferencia y subdivisión de la tierra que -entre otros frutos- llevó a la formación de múltiples unidades productivas y a la aparición de un nutrido racimo de propietarios, arrendatarios y aparceros ${ }^{20}$.

Pues bien: en cada una de estas tareas y momentos participaron propietarios y comerciantes de origen hispano. Si Francisco Armendaiz, Valentín Rivero, la casa Hernández, los Maiz y los Mendirichaga (primos de los Hernández) se contaron entre los que —desde fuera de la Lagunahabilitaron recursos a los agricultores, Leonardo Zuloaga, Santiago Lavín, Rafael Arocena, Francisco Santurtún, Leandro Urrutia, Joaquín Serrano y los Ruiz Lavín estuvieron entre quienes se desenvolvieron en la misma comarca como propietarios y cultivadores del algodón. Ciertamente la Laguna fusionó no pocos de los más poderosos intereses que los españoles dirigían en el centro de México: por un lado, estimuló alguna incursión del ultraporfiriano Íñigo Noriega Laso y de Juan Llamedo; por otro, fue campo propicio para Feliciano Cobián, Policarpo Suso, Saturnino Sauto, Francisco Martínez Arauna y los hermanos (Federico y Sinforiano) Sisniega.

Muchos de estos empresarios no se limitaron al cultivo del algodón: participaron, según los casos, en la puesta en marcha de fábricas transformadoras de la semilla o de la fibra, en la fundación de bancos o en el tendido de medios de transporte. Algunos de ellos pueden ser con-

${ }_{19}$ Ya hacia fines de los ochenta - decía Jorge Vera Estañol en 1910 - la Laguna estaba «en pleno período de desenvolvimiento y progreso, pues año por año en esas tierras había venido ensanchándose la zona de cultivo y habíanse mejorado las obras de irrigación á a la vez que definitivamente se había rechazado de aquella región la presencia de las tribus salvajes. Los campos en otros tiempos áridos e incultos, las tierras pantanosas e inhabitables y las guaridas de las tribus bárbaras se habían convertido en terenos de labor fecundados por obras de irrigación... y en ciudades, haciendas y ranchos bien poblados». Vera Estañol (1910), p. 63.

20 Plana (1996), Vargas-Lobsinger (1984), Meyers (1997). 
siderados de alta representatividad para reflejar lo acaecido en torno al río Nazas desde 1870. Tres casos paradigmáticos fueron el santanderino Santiago Lavín, la misma casa Hernández y la de su protegido y asociado, el vasco Rafael Arocena y Arbide.

\section{Santiago Lavín: de Ampuero al Nazas}

Santiago Lavín fue uno de los actores centrales - y uno de los más polémicos - en el ciclo de ocupación poblacional, financiamiento, redistribución de la tierra y uso agrícola del agua manifestado en la Laguna en los setenta. Fue uno de los pioneros en el cultivo en gran escala del algodón y —de paso- fundador de la actual ciudad de Gómez Palacio.

Su perfil al comenzar los sesenta estaba cincelado por tres características más: a) hijo de José Lavín Ortiz y María Cuadra, era natural de Ampuero, Santander, en el norte de España ${ }^{21}$; b) sumaba menos de treinta años de edad, lo que sugiere que llegó a México en su juventud; $c$ ) prolongó sus iniciales labores mercantiles a las finanzas, lo que habría de convertirlo en prestamista de muchos propietarios y arrendatarios de la naciente comarca.

Fuentes documentales confirman que Lavín actuaba en la Laguna y en el sector productivo ya a principios de los sesenta. La hacienda Santa Cruz, en el estado de Durango, fue una de sus primeras grandes incursiones en el ramo agropecuario. La operaba entonces con su sobrino Francisco Ruiz Lavín. La hacienda La Punta, también en Durango, fue otra de sus tempranas experiencias como productor rural. Hacia fines de los sesenta se lo encuentra conectado con la producción y el comercio de algodón y -muy importante - asociado con el futuro gobernador de Durango, Francisco Gómez Palacio (ambos explotaban a mediados de 1873 La Punta y San Lorenzo) ${ }^{22}$.

Lavín destacó asimismo por ser arrendatario de uno de los tres grandes latifundistas que presidieron la transición hacia el algodón: Juan Ignacio Jiménez. Por medio de mecanismos crediticios, justamente, obtuvo en 1877 la hacienda «Noé» y, a la vez, el derecho a tomar agua de una de las primeras presas levantadas sobre el río Nazas ${ }^{23}$. Para abril de 1878 había

${ }^{21}$ ANED, protocolo de Manuel Puente, enero de 1903, fs. 8v-17. Pablo Machuca Macías (1980, p. 11) indica que nació el 25 de julio de 1834.

${ }_{22}$ Colección Gómez Palacio, Archivo Histórico Papeles de Familia (AHPF, Torreón).

${ }^{23}$ Plana (1996), p. 155. Gracias a un pacto de retroventa, Lavín adquirió esas tierras: al morir Jiménez, su esposa no pudo saldar la deuda/hipoteca y cedió la finca al montañés. 
iniciado la construcción de un nuevo y muy controvertido canal desde la presa «Santa Rosa» (levantada a mediados de siglo por Jiménez) con el fin de irrigar sus flamantes propiedades. Las obras para captar agua - realizadas en la porción de arriba, es decir en el estado de Durangoprovocaron numerosos y tórridos conflictos con los agricultores de rio abajo (del lado de Coahuila), lo que obligó a la intervención de las autoridades federales ${ }^{24}$.

Hacia 1886 la hacienda «Noé» tenía una extensión de más de 30.000 hectáreas, de las cuales unas 10.000 estaban bajo cultivo. Las tierras progresivamente concentradas por el hombre de Ampuero en el lado duranguense de la Laguna habrían de ser conocidas como Perimetro Lavin, muchas veces confundido con su finca mayor: la hacienda «Noé» ${ }^{25}$. Mientras construía este imperio rural en pleno desierto norteño, el dinámico santanderino arrendaba tierras y continuaba prestando dinero a través de

${ }^{24}$ Emiliano Saravia sintetizaba así, en 1909, la historia del santanderino Lavín y la de sus combates por el agua: «Don Santiago Lavín, dueño de la propiedad denominada «El Perímetro», de la que es anexa la presa de «Santa Rosa», y cuya propiedad adquirió por compra a don Juan Ignacio Jiménez en el año de 1880, a pretexto de hacer la limpia del canal de «Santa Rosa», llamado también canal de Lavín, ensanchó sus dimensiones y profundizó su cauce... Como resultado de (diversas) gestiones, la Secretaría de Gobernación (13 de mayo de 1880) y el mismo Gobierno de Durango (16 de mayo de 1880) (no permitieron) la continuación de las obras. En 1881, los señores Lavín y Cía. insistieron nuevamente en el ensanche y profundidad de su canal y nuevamente los vecinos de San Pedro protestaron por esas obras y gestionaron de la Secretaría de Gobernación nuevas órdenes para suspender las obras. (Finalmente) la Suprema Corte mandó destruir las obras que había hecho el señor Lavín, cuya sentencia fue ejecutada por el Juez de Distrito de Durango» (p. 6). Sus propiedades, resume Maria Vargas Lobsinger, eran «un inmenso agostadero que sólo tocaba el río en el extremo sur. Lavín tuvo que luchar tenazmente para abrir el canal» y poder irrigar su enorme propiedad, a la que "convertiría en una de las empresas algodoneras más importantes de la región».

${ }^{25}$ Plana (1996), p. 155; Vargas-Lobsinger (1984), p. 31. Un informe confidencial de 1911 indicaba, por su lado, que el Perímetro Lavín y sus anexos comprendían 50.000 hectáreas. De ellas, 15.000 eran de cultivo. «En años buenos, seguía el informante, las tierras pueden producir en conjunto 90.000 quintales de algodón». Archivo Histórico del Banco Nacional de México (AHBMX, Ciudad de México), Correspondencia Especial de Sucursales, Torreón, 25 de agosto de 1911, vol. 42. Meyers (1997, p. 75) resumió así el itinerario de Lavín: «Con el tiempo, Lavín construyó un enorme sistema de riego y estableció 30 haciendas algodoneras de diversos tamaños y formas, cuyo financiamiento provenía en su mayoría del arrendamiento de las mismas. Su propiedad se convertiría en una de las más valiosas de la Laguna. El Perímetro Lavín abarcaba kilómetros de canales y alojaba una población de más de trece mil personas. En sus propiedades se construyeron estaciones para el Ferrocarril Central y el Ferrocarril Internacional. Sus haciendas tenian nueve despepitadoras de algodón, una extensa red de caminos y un sistema telefónico que unía todos los ranchos con su oficina central, los pueblos de la Laguna y la ciudad de México.» «La hacienda "Noé" — describe Machuca Macias (1991, p. 12) - era la capital del enorme latifundio, tenía bodegas para almacenar las cosechas anuales que se levantaban en sus 
la sociedad comercial Lavín y Cía. Uno de sus arrendatarios más destacados fue el vasco Francisco Santurtún, al que se mencionará más adelante. Rafael Arocena y Leandro Urrutia fueron dos de sus clientes en los años previos a la llegada del ferrocarril ${ }^{26}$.

Por las inacabables tierras de Lavín cruzó la línea troncal del Ferrocarril Central Mexicano: llegó en setiembre de 1883 para unir el centro de México -vía El Paso- con el gigantesco sistema ferroviario estadounidense. En un rincón de los predios del español, cedido de manera especial, se levantó estación Lerdo, a más de 1.100 kilómetros del Distrito Federal. Con otro apeadero - que se enclavó en Torreón, a corta distancia- habría de constituir uno de los escenarios de más rápida urbanización en el México de principios del siglo $\mathrm{XX}$.

Mucho tuvo que ver Santiago Lavín con lo que sucedió en la aislada estación Lerdo. A principios de 1885 inauguró uno de los más interesantes casos de ocupación y poblamiento urbanos en el norte de México. Lo consumó a través de donaciones de predios para ser habitados por individuos, familias, árboles y actividades económicas, todo lo cual quedaba asentado de manera rigurosa y explícita ante el notario ${ }^{27}$. En junio de 1886 Lavín decidió que la población llevaría el nombre de Ciudad Gómez Palacio para «honrar la memoria del esclarecido hijo de Durango», el ex gobernador Francisco Gómez Palacio (su viejo amigo, socio y compadre). Muchas de las calles recordaban el añorado país natal: Santander, Ampuero, Aedo.

Si de muchos españoles que pasaron por la Laguna quedaron débiles rastros o herederos de relativa gravitación en el paisaje local, el apellido

extensas tierras de siembra..., había corrales donde apacentaban cerca de mil mulas y en sus patios se apilaban grandes aperos de labranza.»

${ }^{26}$ ANED, protocolos de José Sariñana, octubre de 1879 , fs. $19 \mathrm{v}-21 \mathrm{v}$; junio de 1880 , fs. $127 \cdot 128 \mathrm{v}$, y marzo de 1881 , fs. $147 \cdot 149$.

${ }^{27}$ Una de las primeras escrituras fue suscrita con Ruperto Enríquez, comerciante avecindado en estación Lerdo, que aceptó las minuciosas y llamativas condiciones impuestas por el santanderino de la hacienda «Noé». Lavín dejó escrito que «animado de los mejores deseos para procurar el mejoramiento de este Municipio» y «procurando la creación de poblaciones que si bien en su principio tropezarán con algunas dificultades», en los terrenos de su propiedad y sobre la vía férrea, conforme al cual pueda levantarse una población» que beneficiaría al Estado, al municipio y a los vecinos que la compongan. Lavín pronosticaba que estación Lerdo era susceptible de crecer gracias «a las transacciones mercantiles que en grande escala se verifican en toda esta comarca, cuya principal fuente de riqueza es la agricultura». Una vez señalada su voluntad de que los terrenos aludidos fuesen cedidos a personas que desearan avecindarse en la nueva población, apuntaba las específicas condiciones de la donación. En ANED, protocolo de José Sariñana, mayo de 1885, fs. $225-227$. 
Lavín no dejó de destacar con fuerza tras la muerte de Santiago (mayo de 1896). A fines del XIX sus hijos constituyeron la sociedad Santiago Lavín Sucesores, que en octubre de 1907 adoptó el nombre Compañía Algodonera e Industrial de La Laguna, S. A. Santiago Lavín Sucesores se constituyó con un capital superior al millón de pesos (medio millón de dólares) ${ }^{28}$. Entre 1898 y 1910 los Lavín intervinieron en algunos de los proyectos industriales y financieros más relevantes de una comarca que ya destacaba a escala nacional por su dinamismo

\section{Los Hernández-Mendirichaga: préstamo, algodón y tierras}

La Laguna fue un escenario fundamental para la mecánica crediticia de la casa Hernández: los registros en Monterrey quedaron asentados desde temprano, en la década de los setenta ${ }^{29}$. Los españoles parecen haber tenido cierta preferencia entre sus babilitados o refaccionados. Claro ejemplo era el vasco Francisco Santurtún, con quien rubricaron convenios en junio de 1874, marzo de 1875 y junio de 1878. Las relaciones con Santurtún respondían al modelo de habilitación que el capital mercantil practicaba con notable agilidad en la Laguna y que puede encontrarse con pertinaz insistencia en las escrituras asentadas en Lerdo ${ }^{30}$.

${ }^{28}$ La estructuración de la sociedad reunió a la viuda Dorotea Vélez y a sus hijos Gilberto, Alejandro, Benjamín y el menor Pablo. Los bienes raíces que se introducian a la sociedad eran los comprendidos en el Perímetro Lavín más la hacienda «Santa Clara» (colindante), los terrenos ubicados en Gómez Palacio y otros bienes inmuebles, semovientes, maquinaria, enseres, créditos y acciones en sociedades de diversa índole. En el inventario realizado se señalaban los ranchos «El Vergel», «San Ignacio», «Filadelfia», «La Torreña», «San Ramón», «Dolores», «Las Playas», «Santander», «San Pedro», «Manila», «Palo Blanco», «San Antonio», «Noé», «Aedo» y la hacienda «Santa Clara» (propiedad exclusiva de Gilberto Lavin, nombrado Administrador General). ANED, protocolo de Manuel Puente, enero de 1903 , fs. $8 \mathrm{v}-17$.

${ }^{29}$ AGENL, protocolos de Francisco García del Corral (1871) y Tomás C. Pacheco (1872). Uno de los biógrafos de la familia recordaba en 1945: «La actuación de nuestra casa en la Laguna fue de mucha importancia, como lo prueba el hecho de haber sido una de las primeras firmas en implantar el negocio de refacción a los agricultores. Entre las firmas refaccionadas por ella debemos citar - sin que fuera la totalidad - las haciendas «San Alberto», «San Esteban», «La Gloria», «El Porvenir», «San Lorenzo», «San Fernando», «Sacramento» y «La Concordia». Algunas de ellas fueron personalmente administradas por nuestros socios». Hernández Mendirichaga (1945), pp. 5 y 6.

${ }^{30}$ Según fuentes notariales, Santurtún procedía de la provincia de Vizcaya. Las primeras referencias sobre su actividad lagunera - relacionadas con Santiago Lavín - son de 1869. Con los Hernández mantuvo una prolongada serie de contratos, con habilitaciones a veces muy importantes. A mediados de 1878 debía en cuenta corriente cerca de cien mil pesos 
Fue en estos años setenta cuando comenzó a sobresalir Ángel Hernández y Luengas. Mariano, el hermano mayor, había regresado a Bilbao a mediados de los sesenta. En Monterrey quedaron Estanislao y Ángel (ambos morirían en México) ${ }^{31}$. Las funciones de Ángel se tornaron importantes desde mitad de la década. En septiembre de 1877 intervino en la reconstitución de la firma, que pasó a denominarse Hernández Hermanos Sucesores ${ }^{32}$. Para fines de los setenta Ángel se encontraba trabajando en Lerdo, la primera villa de importancia en el espacio lagunero. Su actividad estaba fuertemente ligada al préstamo y a la propia agricultura ${ }^{33}$.

El despuntar de este Hernández en los registros de Lerdo es casi paralelo al del vasco Rafael Arocena, de quien se convirtió en asociado y amigo de confianza. Arocena arribó a la Laguna cuando comenzaba a tornarse significativa la agricultura del algodón merced, justamente, a la actuación de firmes mercantiles como Hernández Hermanos Sucesores, con cuyo representante local compartió numerosos proyectos ${ }^{34}$.

Un elemento que contribuyó a anudar la relación entre los Hernández y Arocena fue la hacienda «Santa Teresa». Ubicada en San Pedro de las

(unos 70.000 dólares de la época). Datos sobre Santurtún en AGENL y ANED, libros de notarios, y en AHPF, colección Gómez Palacio.

${ }^{31}$ Ángel Hernández había comenzado a participar en la firma en marzo de 1865, en lugar del primo Nicolás Josué Hernández. Cuando Mariano se marchó al País Vasco quedaron los tres hermanos menores a cargo de la empresa. AGENL, protocolos de Tomás C. Pacheco (1865) y Pablo Borrego (1874-1876).

32 Su capital inicial ascendió a 35.000 pesos, de los cuales 5.000 correspondían a Ángel. AGENL, protocolo de Pablo Borrego, setiembre de 1877, fs. 194v-197v. En 1882 la sociedad sufrió otra modificación. Fueron incorporados dos sobrinos: Félix y Tomás Mendirichaga y Hernández. Como su primo Tomás Mendirichaga y Llaguno, que también trabajaba en el norte de México, provenían del espacio limítrofe de Trucios. Félix y Tomás eran hermanos de Julita Mendirichaga, casada con Estanislao Hernández y Luengas, jefe de la familia en México. Mariano, en tanto, seguía en Bilbao hacia fines de siglo, según registros notariales de Vizcaya.

${ }^{33}$ Los deudores solían ser gente de alta significación económica, grandes propietarios. En febrero de 1880 los Hernández eran acreedores de doña Luisa Ibarra, la viuda de un vasco legendario en la historia regional, Leonardo Zuloaga. Otra ilustre deudora a principios de los ochenta era Elvira San Martín, viuda de uno de los grandes latifundistas de la época heroica (1850-1865), Juan Ignacio Jiménez. ANED, protocolos de José Sariñana, 1880-1881. Por estos tiempos ya residía en Lerdo Félix Mendirichaga, sobrino de Ángel. Con su hermano Tomás llevarian en buena medida la dirección de la casa Hernández luego de la muerte de Estanislao y Ángel. Tomás, que vivió siempre en Monterrey, tejería una amplia relación con la comarca algodonera y, como se verá, con no pocos de sus principales proyectos empresariales.

${ }^{34}$ Seguramente fue por esa confianza que Arocena designó a Ángel Hernández en marzo de 1884 -en su testamento o «última disposición»- ejecutor especial de su voluntad. ANED, protocolo de José Sariñana, marzo de 1884, fs. 48-50. 


\section{MAPA 2}

Principales propiedades en la Laguna (1910)

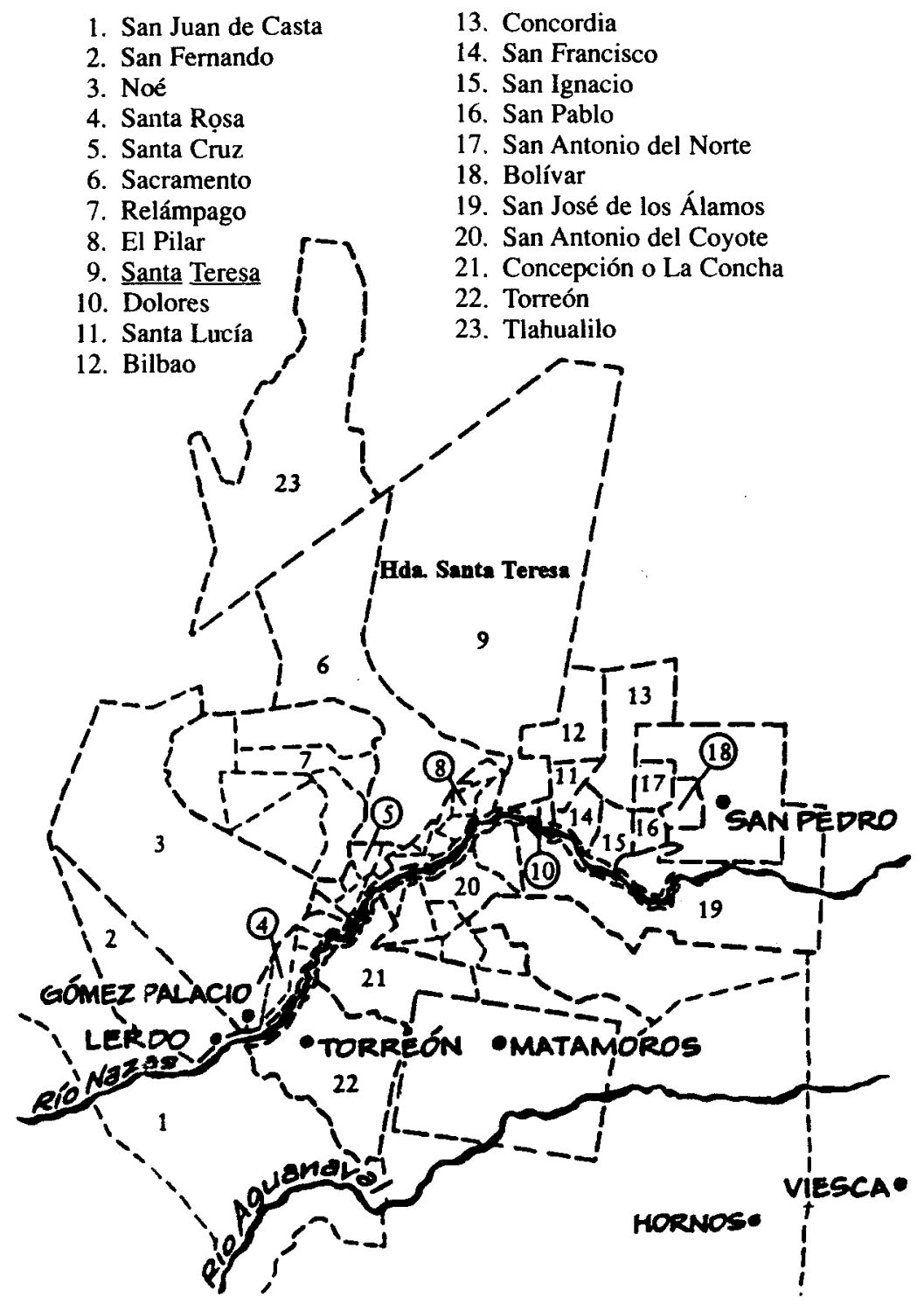


Colonias (mapa 2), esta enorme propiedad fue adquirida y administrada por la casa Hernández: una nítida expresión del impacto del capital mercantil sobre la propiedad rural y la explotación agrícola especializada ${ }^{35}$. «Santa Teresa» era la más grande de todas las propiedades existentes en la Laguna a fines del XIX. Al morir Estanislao Hernández y Luengas, en 1887, la hacienda - valuada en cerca de 45.000 dólares- se componía de unas 110.000 hectáreas ${ }^{36}$. «Santa Teresa» habría de transformar a Rafael Arocena en uno de los principales agricultores de la Laguna y en uno de los más sobresalientes propietarios de origen español.

\section{Rafael Arocena: en el reino del algodón}

Las mútiples referencias sobre este vasco coinciden: los asociados que tuvo, la deferencia que le dispensaban sus contemporáneos, su participación en la producción de algodón y semilla, su privilegiada incorporación a proyectos empresariales agroindustriales, los peculiares problemas que debió enfrentar durante la revolución y la manera como logró sortearlos lo definen como un personaje de primera línea de los tiempos porfirianos.

Rafael de Arocena y Arbide era originario de la anteiglesia de Arrancudiaga, provincia de Vizcaya, donde nació en octubre de $1847^{37}$. Existen dudas sobre el momento preciso en que llegó a México y sobre cuándo se estableció en la Laguna. Es muy posible que lo haya efectuado a través de la casa mercantil que regentaban los Muñuzuri, uno de cuyos integrantes

35 «Santa Teresa» había estado ubicada en la zona baja de la hacienda «San Lorenzo» de la Laguna, que había pertenecido a la poderosa familia Sánchez Navarro y vendida en 1848 al español Leonardo Zuloaga y al mexicano Juan Ignacio Jiménez. Junto con «El Alamito» y «Jaboncillo», «Santa Teresa» fue transferida en 1877 a Eduardo Ávila, un agricultor que - con suma frecuencia - era habilitado por casas de Monterrey. Al morir Avila en 1879 , sus tierras fueron sucesivamente transferidas hasta que en 1881 «Santa Teresa» pasó a manos de Hernández Hermanos. Vargas-Lobsinger (1984), pp. 28-29; Plana (1996), pp. 84-85 y 111-113; AMS, protocolo de Francisco Pérez, enero de 1896, fs. 10v-18.

${ }^{36}$ AGENL, protocolo de Tomás C. Pacheco, marzo de 1995, fs. 308v-325.

${ }^{37}$ Fue el tercer hijo de Santiago de Arocena Barbachano -nacido en Ceberio en 1819y de Victoriana Arbide, natural de Arrancudiaga. ANED, protocolo de José Sariñana, marzo de 1884, fs. 48-50; AHPF, Colección Arocena, acta de bautismo. Arocena falleció en Nueva York a mediados de 1919. Fue uno de los muchos españoles que emigró con la Revolución, período particularmente duro para esta colonia extranjera en la comarca lagunera. Sus bienes, inicialmente confiscados por Francisco Villa, fueron luego recuperados y manejados por su sobrino y yerno Francisco Arocena. Sobre los problemas soportados por los españoles en el norte véase Flores Torres (1995 y 1997), Zuleta (1997) y Cerutti (1995). El accidentado itinerario de las propiedades de Arocena en AB, Copiadores y Correspondencia, y en AHPF, Colección Arocena. 
-Antero- poseía terrenos en 1867 al sur de la hacienda San Fernando en la parte duranguense de la comarca. Se dispone información más ajustada, empero, del nacimiento de su primera hija (Zenaida Arocena Ávila), en octubre de $1878^{38}$.

La primera mención notarial detectada sobre Arocena es de comienzos de la década de los ochenta, dos años y medio después del nacimiento de Zenaida. Como en el caso de su futuro socio Leandro Urrutia (también vasco), Arocena parece haber entrado al especializado mundo del algodón como arrendatario de Santiago Lavín: en marzo de 1881 comenzó a trabajarle la finca «San Antonio». Según El Siglo de Torreón, fue justamente en el rancho «San Antonio» donde Arocena utilizó por primera ocasión, hacia 1882, semilla de origen estadounidense. La difusión de esta semilla en la Laguna habría provocado un drástico cambio tanto en la productividad como en la rentabilidad de los cultivos ${ }^{39}$.

Numerosos rastros documentales permiten confirmar que la poderosa casa Hernández acogió en algún momento de la década de los ochenta al vasco de Arrancudiaga. Su historia inicial como agricultor y su conversión en un poderoso productor y propietario estuvieron anudados con tenacidad a la experimentadísima firma de Monterrey. Esta articulación quedó soldada en febrero de 1886, cuando se constituyó una sociedad agrícola que reunió a la sucursal Lerdo, de Hernández Hermanos Sucesores -representada por Ángel Hernández-y al propio Arocena: se conformó para explotar la hacienda «Santa Teresa». En sentido estricto, la sociedad agrícola Hernández y Arocena fue una prolongación operativa de los negocios de Hernández Hermanos en la Laguna. Un año después de su constitución ambos socios reconocían una fuerte deuda -en términos contables- en la cuenta corriente que les había abierto la casa de Monterrey: ascendía

${ }^{38}$ Esta niña fue fruto de su relación con Ambrosia Ávila y Torres, a quien debió conocer en la segunda fracción de los setenta, con quien nunca formalizó su matrimonio y con quien tuvo otro hijo, Adolfo, fallecido años después. AHPF, Colección Arocena, acta de bautismo de Zenaida Arocena Ávila. La referencia sobre los Muñuzuri en Carlos Hernández, 1903, p. 105.

${ }^{39} \mathrm{El}$ contrato de arrendamiento del rancho «San Antonio» (municipio de Lerdo) en ANED, protocolo de José Sariñana, marzo de 1881, fs. 147-149. Sobre la semilla, El Siglo recordaba en 1932 que Arocena la había introducido por Matamoros y «la condujo por tierra en carretas hasta el Perímetro Lavín, de cuya hacienda era arrendatario (y) en cuyas labores se cultivó por primera vez y con éxito. De las semillas del primero, segundo y tercer año de aquella variedad extranjera vendió el señor Arocena a otros agricultores... y el uso fue extendiéndose; cuando el tráfico de ferrocarril quedó generalizado, se generalizó por completo el uso de la semilla norteamericana en sus distintas variedades». 
a casi 100.000 pesos (50.000 dólares), insumidos en «costosísimas obras para el cultivo y explotación» 40 .

Primera gran experiencia agro-empresarial conocida de Arocena, la sociedad se disolvió en diciembre de 1891. Los resultados, si se atiende a lo manifestado documentalmente, no habrían sido espectaculares. Pero el panorama o el futuro de «Santa Teresa» no debió ser tan negativo, porque en el mismo día que se documentó la disolución de la anterior sociedad (19 de enero de 1892) Arocena adoptó y suscribió dos decisiones fundamentales: se asoció con su paisano Leandro Urrutia y ambos tomaron en arrendamiento la hacienda. Comenzaba entonces, en pleno auge del porfiriato, la historia de uno de los más grandes empresarios de la agricultura en el norte de México.

\section{EL AUGE PORFIRIANO (1885-1910)}

Tanto el desarrollo del cultivo algodonero como el paralelo desenvolvimiento financiero e industrial de la Laguna germinó estimulado por capitales procedentes de Chihuahua, Monterrey, Saltillo y la ciudad de Durango, a los que se sumaron significativos recursos provenientes de la ciudad de México. La impresionante transformación que vivió la Laguna entre 1870 y la Revolución manifestaba, al menos, otras cuatro aristas: a) la gestación de un ágil grupo empresarial local; $b$ ) este grupo no sólo reinvertía en el escenario lagunero ${ }^{41}$, sino que, simultáneamente, bifurcaba sus capitales para encadenarse y apoyar el notorio crecimiento que vivían plazas como Chihuahua y Monterrey; c) la articulación de un eje económico y empresarial que bajaba de Chihuahua, se anudaba en la Laguna y remataba

\section{fs. $80 \mathrm{v}-82$.}

40 ANED, protocolos de José Sariñana, marzo de 1887, fs. $15 \mathrm{v}-17$, y enero de 1892 ,

${ }^{41}$ Una enumeración suscinta de los establecimientos fabriles, de servicios y bancarios levantados desde mediados de los ochenta en el corazón urbano de la Laguna (Lerdo, Gómez Palacio y Torreón) debe incluir: La Esperanza, La Amistad, La Alianza, Fábrica de Calzados La Unión, Compañía Industrial Jabonera de la Laguna, Compañía Industrial Algodonera de la Laguna, El Brillante, Ferrocarril Eléctrico de Lerdo a Torreón, Compañia Cervecera de Torreón, Compañía Ladrillera de Gómez Palacio, El Fénix, La Victoria, La Nacional, La Constancia, Compañía de Luz y Fuerza de Gómez Palacio, Compañía de Luz Eléctrica de Torreón, La Fe, Jabonera La Unión, Compañía Metalúrgica de Torreón, Continental Mexican Rubber Co., Compañía Guayulera de Torreón, Compañía de Inversiones y Descuentos, Banco de la Laguna, Banco Chino y sucursales o agencias de los bancos Nacional de México, de Nuevo León, Mercantil de Monterrey, Comercial de Chihuahua, Minero de Chihuahua, de Coahuila, de Durango y Agrícola Hipotecario. 
en Monterrey, eslabonamiento crucial para la puesta en marcha de importantes sociedades anónimas dentro de la dinámica global del norte ${ }^{42}$; d) en tal accionar empresarial tuvieron una amplísima participación muchos españoles y sus descendientes más inmediatos. Su comportamiento - tanto en la Laguna como en ese espacio fronterizo mayor encerrado entre la Sierra Madre Occidental, Texas y el Golfo de México- será revisado en este apartado.

\section{Tiempos de agroindustria}

En este lejano norte los desiertos eran sacudidos desde mediados de los ochenta por el tendido de las grandes líneas ferroviarias que descendían de los Estados Unidos. Entre 1882 y 1888 quedaron habilitados los ferrocarriles Central, Internacional y Nacional, todos convergentes hacia el río Bravo y hacia Texas ${ }^{43}$. Debajo del Bravo se formaron dos estratégicos nudos de comunicaciones: Monterrey y la propia comarca lagunera, pivotes regionales por la diversidad de ramales que corrían hacia otros puntos del norte y del centro del país.

\section{La Esperanza}

Si los agricultores dispararon su producción cuando el ferrocarril les acercó la industria textil de Puebla, Veracruz y el valle de México, los grupos mercantiles de Monterrey resolvieron pasar a la inversión industrial directa: en junio de 1887 fundaron La Esperanza, una fábrica para la elaboración de aceites, jabón y otros derivados de la semilla de algodón. La

\footnotetext{
${ }^{42}$ Sobre la formación y funcionamiento de este eje empresarial antes de la Revolución, Cerutti (1994b).

${ }^{43}$ Los rieles atravesaron el gran norte centro/oriental mexicano y lo conectaron con la economía estadounidense en un triple sentido: a) acentuaron sus vinculaciones con el potente Estado de Texas, que hacia 1895 sumaba 15.000 kilómetros de vías y se encontraba completamente integrado al mercado nacional de los Estados Unidos; $b$ ) lo unieron con la porción central del territorio vecino (el medio oeste) y con la zona de los grandes lagos que rodea a Chicago, hacia cuyos corrales y empacadoras (enlatadoras) fluían miles de cabezas de ganado; c) y, en especial, anudaron firmes lazos con el noreste atlántico, uno de los principales escenarios de la segunda revolución industrial. El papel de Texas en este proceso articulador resultó sustancial: en 1910 la extensión de sus ferrocarriles era mayor a la de todo México (México sumaba ese año casi 20.000 kilómetros de vías: su red, por tanto, casi duplicaba la española y era un 20 por 100 mayor a la italiana). Reed (1981), p. 512; Gómez Mendoza, (1982).
} 
Esperanza —que se levantó en Gómez Palacio, la villa recién fundada por el santanderino Santiago Lavín- estaría destinada a simbolizar el aglutinamiento de múltiples y vivaces capitales regionales. Su constitución y desarrollo supuso - de paso- la reafirmación de la importancia de los empresarios de origen hispano en esta economía de frontera.

Como La Esperanza reunió en su momento fundacional, sobre todo, a comerciantes de Monterrey ${ }^{44}$, no podían faltar mercaderes peninsulares. La presencia de la casa Hernández Hermanos - y de sus flamantes administradores, los Mendirichaga - era una prolongación casi natural de casi dos décadas de inversiones en la comarca. Su pasaje de la múltiple condición de comerciantes, prestamistas, intermediarios en el tráfico del algodón, propietarios de tierras y agricultores a la de productores fabriles era, en la misma Laguna, un dato más del proceso general que se vivía en las más dinámicas regiones de México tras las reformas liberales. Félix Mendirichaga (quien tiempo después se marchó a Bilbao) fue designado Secretario de la primera Junta Directiva. La representación hispano/regiomontana fue completada más tarde por los hermanos Maiz ${ }^{45}$.

El embrionario eje empresarial se prolongó hacia Chihuahua en 1892, cuando La Esperanza («para evitar una competencia ruinosa») se fusionó con La Nacional, una pequeña pero muy agresiva firma nacida en 1884 . Lo particularmente llamativo de La Nacional era que sus creadores habían sido el chihuahuense Juan Terrazas y John Brittingham, joven estadounidense que había llegado de San Louis Missouri en diciembre de $1883^{46}$

${ }^{44}$ La escritura constitutiva de La Esperanza quedó asentada en Monterrey. AGENL, protocolo de Tomás C. Pacheco, junio de 1887, fs. 84v-86v.

${ }^{45}$ En 1895 se efectuó una fuerte reestructuración en la empresa. Para entonces estaban registrados como accionista los hermanos vascos Justo, Ángel y Pedro Maiz. También estaba incorporado Juan Terrazas, hijo del general Luis Terrazas (ex combatiente liberal, ex cazador de apaches, gobernador, hombre fuerte del Estado de Chihuahua, caudillo regional, ganadero y gran terrateniente en el área fronteriza). AGENL, protocolo de Tomás C. Pacheco, septiembre de 1895 , fs. $770-71 v$.

${ }^{46}$ John Brittingham y Juan Terrazas fueron condiscípulos en un colegio de San Louis Missouri. Fue para visitar a su amigo que Brittingham llegó a Chihuahua en diciembre de 1883. Sumaba veintitrés años de edad. Con La Nacional, ambos jóvenes iniciaron una carrera empresarial que en el caso de Brittingham fue particularmente exitosa. Sobre La Nacional, su instalación y la competencia que entre 1888 y 1892 mantuvo con La Esperanza, Archivo Brittingham ( $\mathrm{AB}$, Monterrey), Copiadores, 17 y 18 de enero de 1898. Dos consecuencias de la fusión de ambas empresas fueron: a) Brittingham y Terrazas quedaron ligados como accionistas a La Esperanza; b) Brittingham se trasladó a Gómez Palacio y se convirtió en su Director General, cargo que ocupó hasta mediados de los años veinte. El estadounidense Brittingham, el mexicano Terrazas, el irlandés Francisco Belden y el español Tomás Mendirichaga y Hernández (estos últimos residian en Monterrey) integraron 
Cuando La Esperanza se convirtió en la Compañía Industrial Jabonera de la Laguna, S. A., el 1 de setiembre de 1898, la construcción del eje Chihuahua/La Laguna/Monterrey avanzó un nuevo peldaño y, por supuesto, se expandió la concurrencia hispana. La transformación fue fruto de un proyecto de John Brittingham, gerente de La Esperanza desde 1892, con el respaldo de Juan Terrazas, Francisco Belden y el vasco-santanderino Tomás Mendirichaga y Hernández. Para asegurar a la planta de Gómez Palacio un aprovisionamiento regular y a precios estables de la semilla de algodón el estadounidense propuso fusionar la empresa que dirigía con otras tres productoras locales e invitó a los más poderosos agricultores a convertirse en accionistas de la nueva sociedad ${ }^{47}$.

Al fraccionarse el capital inicial de Jabonera (un millón de dólares) en 20.000 acciones se acordó que la mitad correspondiera a los agricultores. El 50 por 100 restante quedó en manos de los industriales. Se constituyó así un sindicato que controlaba de manera casi monopólica la producción, recolección, flujo y utilización de la semilla y que - por la evidente influencia que ejercía sobre el mercado global del jabón - iba a obtener beneficios espectaculares. Como convirtió en accionistas a los más encumbrados propietarios/agricultores de la Laguna, no debe asombrar que entre sus asociados sobresaliera en los primeros años un reconocible grupo de españoles (cuadro 3).

Del lado de los accionistas industriales figuró de manera destacada Tomás Mendirichaga y Hernández: lo hizo por sí y en representación de Sucesores de Hernández Hermanos, y fue miembro del primer Consejo de Administración. Maíz Hnos. mantuvo la presencia que traía desde mediados de los noventa. La novedad fue que otro poderoso vasco de Monterrey -Francisco Armendaiz - se plegó a la lista de accionistas. Entre los agricultores destacaban largamente Rafael Arocena y su socio, Leandro Urrutia. El asturiano Feliciano Cobián, Ulpiano Ruiz Lavín (sobrino del ya extinto Santiago), Saturnino Sauto y Joaquín Serrano se contaron entre los asociados.

desde mediados de los noventa un staff que tuvo decisiva participación en destacados proyectos empresariales en el norte de México.

$47 \mathrm{La}$ información que sigue ha sido extraída en su mayor parte de Libros Copiadores y Correspondencia (1895-1913) del Archivo Brittingham. Sobre los orígenes y desarrollo de Jabonera, Cerutti (1997). 


\section{CUADRO 3}

Españoles accionistas de Jabonera (1898-1908)

\begin{tabular}{|c|c|c|}
\hline Nombre & Lugar de residencia & Principal actividad \\
\hline Rafael Arocena..... & La Laguna & Agricultor \\
\hline Leandro Urrutia .............................. & La Laguna & Agricultor \\
\hline 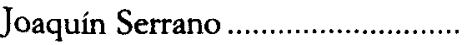 & La Laguna & Industrial/agricultor \\
\hline Carlos Arriaga ................ & La Laguna & Agricultor \\
\hline José María Urrutia ........................ & La Laguna & Agricultor \\
\hline Ulpiano Ruiz Lavín ........................ & La Laguna/Santander & Agricultor \\
\hline Andrés Medellín............. & La Laguna & Agricultor \\
\hline 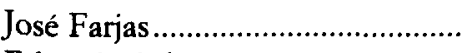 & La Laguna & Ingeniero/agricultor \\
\hline Eduardo Sobrino .................... & La Laguna & Agricultor \\
\hline 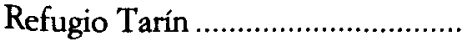 & La Laguna & Agricultor \\
\hline 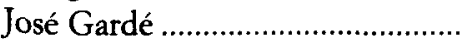 & La Laguna & Agricultor \\
\hline Fco. Martínez Arauna ..................... & México DF & Comercio/agricultor \\
\hline Feliciano Cobián ............................... & México DF & Comercio/agricultor \\
\hline 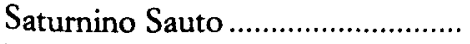 & México DF & Industrial \\
\hline Tomás Mendirichaga ..................... & Monterrey & Comercio/industrial \\
\hline 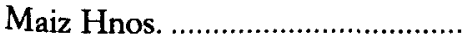 & Monterrey & Comercio/industrial \\
\hline F. Armendaiz Sucesores ................. & Monterrey & Industrial/comercio \\
\hline Sucs. de Hernández Hnos............. & Monterrey & Comercio/finanzas \\
\hline
\end{tabular}

FuENTE: AB, Copiadores y Correspondencia, 1895-1912; ANED, protocolo de José Zurita, 4 de octubre de 1898, fs. 6-29v.

La andadura de la sociedad - respaldada por la creciente elaboración de alimentos animales, pasta aceitosa (cake, que se exportaba a Inglaterra) $y$, desde principios de siglo, de glicerina - resultó lo suficientemente exitosa como para brindar excelentes dividendos y para efectuar tres sucesivos aumentos de capital: cuando en 1907 alcanzó los cinco millones de pesos (unos dos millones y medio de dólares) Jabonera era una de las más grandes fábricas de su sector en América Latina.

\section{Los prósperos agricultores del algodón}

Arocena, Urrutia, «Santa Teresa»

Leandro Urrutia, de origen vasco, fue socio de Rafael Arocena hasta su muerte, en 1908. La primera referencia sobre Urrutia se detectó en octubre 
de 1879, cuando celebró un contrato de arrendamiento con el ya poderoso Santiago Lavín por el rancho «San Ignacio». Tiempo después lo encontramos como arrendatario de porciones de la misma hacienda «Santa Teresa» ${ }^{48}$. Estos datos permiten suponer que para 1892 Urrutia contaba con amplia experiencia, conocía «Santa Teresa» y gozaba de cierto espaldo económico.

El contrato colectivo que selló la sociedad Arocena y Urrutia con la casa Hernández Hermanos — citado más arriba - estaba concentrado en la explotación de esta enorme propiedad. Pero el ciclo iniciado por ambos vascos durante la década de los setenta habría de rematar en 1897, cuando pasaron a ser propietarios de «Santa Teresa», una operación cubierta con 400.000 pesos (200.000 dólares, la mitad al contado) ${ }^{49}$. «Santa Teresa» era hacia 1910 la propiedad de mayor extensión en la Laguna. Su sistema de riego - tomado del río Nazas - tenía dos canales principales: el Cuije, en su parte oriental, y el de la Vega, en la occidental. Gracias a esos canales y sus derivaciones se hacían funcionar una veintena de ranchos ${ }^{50}$. En tiempos posteriores a la revolución «Santa Teresa» sumaba alrededor de 70.000 hectáreas: de ellas, 25.000 eran de riego, y el resto, de agostadero. Casi todos los ranchos se encontraban unidos por más de 100 kilómetros de vías tipo Decauville, con ramales hacia la colindante hacienda «Bilbao». Todo el sistema interno de transporte se articulaba en la estación Santa Teresa al Ferrocarril Central, que unía la ciudad de México con El Paso, en Texas. No puede extrañar que «Santa Teresa» se convirtiese desde finales de los noventa en una de las fincas que más cosechaban algodón y semilla. El cuadro 4, aunque basado en estimaciones no totalmente confiables, permite observar el porcentaje de fibra que sumaba a la Laguna. Con frecuencia osciló entre 11 y 18 por 100 , aunque con más asiduidad variaba entre el 4 y el 9 por 100 del total.

\section{Cobián, Serrano, Ruiz Lavín}

Otro caso muy llamativo fue el del asturiano Feliciano Cobián. Tras ejercer el comercio en Guadalajara se instaló en la ciudad de México,

${ }^{48}$ ANED, protocolos de José Sariñana, octubre de 1879, junio de 1880 y julio de 1888.

49 ANED, protocolos de José Sariñana, enero de 1892, fs. 82-86, y abril de 1897, fs. $43 \mathrm{v}-48 \mathrm{v}$.

so Con El Cuije se regaban los ranchos «Lequeitio», «Colón», «Covadonga», «La Pinta», «Finisterre», «San Juan», «Santa María», «La Niña» y «El Salvador»; con el canal de la Vega se irrigaban las fincas «Santa Teresa», «La Fe», «Vega Larga», «Begoña», «Victoria», «Santa Anita», «Sofía», «Nuevo Mundo» y «El Cántabro». 


\section{CUADRO 4}

Producción en la Laguna y en Santa Teresa (1897-1912) (en quintales de $47 \mathrm{~kg}$.)

\begin{tabular}{cccc}
\hline Año & Comarca & «Santa Teresa» & «Santa Teresa»/Laguna (\%) \\
\hline 1897 & 382.700 & 42.270 & 11,40 \\
1898 & 551.700 & 99.810 & 18,09 \\
1899 & 430.000 & 33.650 & 7,82 \\
1900 & 374.300 & 20.310 & 7,83 \\
1901 & 319.800 & 14.610 & 4,56 \\
1902 & 348.000 & 14.570 & 4,18 \\
1903 & 365.300 & 13.690 & 3,74 \\
1904 & 339.000 & 20.250 & 5,97 \\
1905 & 402.700 & 45.470 & 11,92 \\
1906 & 745.200 & 52.940 & 7,04 \\
1907 & 801.000 & 77.770 & 9,70 \\
1908 & 341.400 & 38.740 & 11,34 \\
1909 & 374.400 & 14.990 & 4,00 \\
1910 & 411.100 & 100.280 & 24,39 \\
1911 & 471.200 & 71.230 & 15,11 \\
1912 & 322.000 & 45.100 & 13,99 \\
\hline
\end{tabular}

FuENTE: AHPF, Colección Arocena, ingeniero Federico Wulff, mapa y cuadro de producción de la comarca lagunera, 1912.

donde durante años dirigió la casa Feliciano Cobián y Hno., que hacia 1908 contaba con una sucursal en Torreón. En la Laguna comenzó a operar al iniciar los noventa, tras asociarse con otro comerciante español: Francisco Martínez Arauna. En esta sociedad intervino también un hermano de Feliciano, Prudencio Cobián. Dos de las actividades centrales de esta firma eran el préstamo y la compraventa de algodón, mecanismos que siempre marchaban a la par.

Cobián se transformó en pocos años en un poderoso agricultor. Arrendó y compró tierras en vasta escala. Entre 1890 y 1909 usufructuó ranchos y haciendas como «Perú», «Palma», «Partida», «San Luis», «San Antonio de los Bravos», «Pajonal», «Guadalupe», «San Felipe», «Corona», «La Perla», «San Juan de Tlahualilo», «La Joya» y anexas, «Las Vegas», «Torreón» y anexas, «San Antonio» y «Avilés». John Brittingham lo consideraba «uno de los más fuertes productores de la Laguna», con cosechas de semilla que alcanzaba las 5.000 toneladas anuales. Fue accionista, entre 
otras empresas, de La Alianza, La Unión, Jabonera y el Banco de la Laguna, aunque sobresalía entre los más acérrimos adversarios de Brittingham. Como Cobián - tras vender sus acciones en Jabonera-, se negaba a aceptar la entrega obligatoria de semilla a la aceitera de Gómez Palacio, soportó dos serios choques jurídicos con Brittingham. El último terminó en 1910 en la Corte Suprema, que falló en contra del español. Previamente Jabonera había promovido el embargo de las propiedades de Cobián en la comarca ${ }^{51}$.

Otro caso notable fue el de Joaquín Serrano. Su procedencia exacta - dentro del norte español — no se ha podido precisar, aunque se le supone asturiano o santanderino. Serrano - a diferencia de Feliciano Cobián y los hermanos Sisniega - vivía en la Laguna. Otra distinción era su interés en el desenvolvimiento fabril de Torreón. En todos los registros notariales consultados Serrano aparece como agricultor. Pero, curiosamente, esos registros mencionan su dinamismo y persistencia en otras actividades, muchas de ellas de sesgo industrial. Estuvo vinculado desde el principio a la Compañía Industrial Jabonera de la Laguna, aunque lo hizo como presidente de la sociedad anónima La Unión, cuya fábrica se pretendía instalar en Torreón cuando Brittingham lanzó la idea de vincular La Esperanza a los productores de semilla. En La Unión -que se había constituido en octubre de 1897- se encontraban algunos de sus socios de costumbre: el ingeniero español José Farjas, el vasco José María Urrutia, el navarrés Carlos Arriaga y el licenciado Prágedis de la Peña, propietario de la hacienda «El Pilar», distinguido vecino de Saltillo y futuro gobernador de Coahuila.

A fines de siglo, cuando se vivía una verdadera euforia de negocios en la comarca, Serrano participó en la fundación de varias empresas. Una de ellas fue la Compañía Industrial de Hilados y Tejidos de Algodón «La $\mathrm{Fe}, \mathrm{S}$. A.», que hacia mayo de 1899 sumaba un capital de 600.000 pesos (300.000 dólares). Serrano, de nuevo, era el presidente del Consejo de Administración y entre los accionistas destacaban un buen número de coterráneos (poseían casi las tres cuartas partes de las acciones, cuadro 5).

En 1898 y 1899 Serrano intervino en la creación de la Cervecería de Torreón (fue miembro del Consejo de Administración), la instalación de una sucursal del Banco de Coahuila en la misma ciudad, la puesta en

${ }^{51}$ La imagen de este asturiano asume perfiles espectaculares cuando se recuerda que fue dueño de una lujosa residencia en la calle Bucareli, en la ciudad de México. En 1908 trocó esta finca urbana por la hacienda de «San Isidro», en Jalisco. El palacio de Bucareli - que luego pasaría a ser sede de la Secretaría de Gobernación- fue entregado a cuenta: valía unos 450.000 dólares. Vargas-Lobsinger (1984), pp. 58-63; Plana (1996), pp. 169-170 y 179-180; Cerutti (1985), pp. 143-144. 


\section{CUADRO 5}

Accionistas de «La Fe» (mayo de 1899)

\begin{tabular}{|c|c|}
\hline Nombre & Acciones \\
\hline Joaquín Serrano * & 2.250 (sobre 6.000 ) \\
\hline 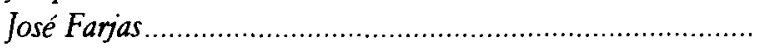 & 750 \\
\hline Prágedis de la Peña & 600 \\
\hline Federico Crespo * & 500 \\
\hline Eduardo Sobrino*. & 450 \\
\hline Prudencio Cobián *.. & 450 \\
\hline 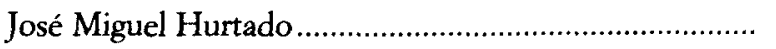 & 375 \\
\hline 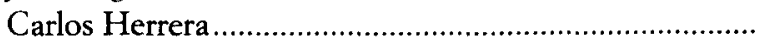 & 300 \\
\hline Pablo Schugt & 150 \\
\hline 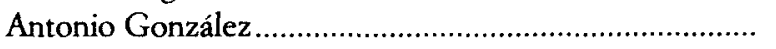 & 150 \\
\hline Juan C. Farjas (hijo) & 15 \\
\hline 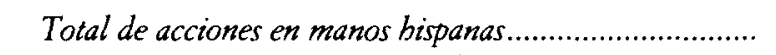 & 4.400 \\
\hline Porcentaje de acciones propiedad de españoles ................ & 73,33 \\
\hline
\end{tabular}

* Accionistas de origen hispano comprobado. de 1899.

FUENTE: AGEC, Protocolo de Eugenio Gaytán, 30 de marzo de 1898 y 7 de mayo marcha de una sociedad minera que explotó un socavón en el partido de Mazapil, Zacatecas, y se hizo cargo con José Farjas de una concesión estatal que autorizaba usufructuar el alumbrado público en Torreón. En 1907, además, se contó entre los accionistas del Banco de la Laguna ${ }^{52}$.

Los Ruiz Lavín -Ulpiano, Francisco y Antonio, sobrinos de Santiago Lavín y procedentes de Ampuero, Santander - también tuvieron una notoria participación en agricultura, comercio y finanzas. Ulpiano fue uno de los más grandes prestamistas para-bancarios locales, agricultor de relevancia - sobre todo en la hacienda «Bilbao»-y asociado a varias de las empresas industriales que hemos descripto, entre ellas Jabonera de la Laguna (con Joaquín Serrano integró el grupo de vocales suplentes de esta sociedad). Antonio, por su lado, dirigió durante años la firma mercantil Antonio Ruiz Lavín y Cía. Cuando Ulpiano marchó a Santander, en la primera década del siglo $\mathrm{xx}$, fue Ruiz y Cía, la firma encargada de continuar ejerciendo el préstamo refaccionario ${ }^{53}$.

\footnotetext{
32 AMS y AGEC, libros de notarios; AB, Correspondencia.

53 ANED, AMS, AGEC, libros de notarios.
} 


\section{El Banco de la Laguna}

El Banco Refaccionario de la Laguna, S. A., que comenzó a operar en 1907, es otro excelente ejemplo para verificar cómo los españoles se asociaban y eran aceptados por los más ilustres empresarios del norte. Su fundación resultó un suceso que en muchos sentidos no deja de impresionar. En primer término, por la rapidez con que fue puesto en marcha. Luego, porque su capital de arranque —unos tres millones de dólaresfue suscrito en alrededor de treinta días en la misma Laguna y en sus habituales puntos de apoyo (Monterrey, Chihuahua, Durango, Saltillo). Finalmente, porque su inauguración se protagonizó en medio de la más severa crisis económica soportada por el porfiriato, en pleno 1907.

Juan F. Brittingham - ya citado- fue de nuevo el promotor principal. Brittingham había mantenido durante los primeros años del siglo una estrecha vinculación con la actividad bancaria: se había asociado con el chihuahuense Enrique C. Creel -yerno del general Luis Terrazas- en el Banco Hipotecario de Crédito Territorial, había orientado la sucursal local del Banco Comercial de Chihuahua, fue accionista destacado del Banco Minero de Chihuahua y del Banco de Tamaulipas e integró el grupo ampliado que fundó en la ciudad de México el poderoso Banco Central Mexicano. Estos antecedentes, la experiencia que vivió en La Esperanza y en la Compañía Industrial Jabonera y la recurrente prosperidad agroindustrial local moldearon el proyecto de 1907: se trataba de un banco regional destinado en primera instancia a estimular la propia economía lagunera y su entorno más inmediato.

Hacia marzo de 1907 Brittingham se encontraba embebido en la tarea de detectar e incorporar suscritores para la creación de un banco refaccionario, una de las tres categorías reglamentadas por la Ley de Instituciones de Crédito de 1897. El 28 de ese mes remitió a Luis Gurza -el más sobresaliente empresario de la ciudad de Durango- una lista posible de candidatos. Estimaba prudente en ese momento «conseguir una suscrición que llegara a los cinco millones de pesos para crear una institución de crédito de una vez formal y poderosa». Por ese motivo, narraba, había estado escribiendo a «todos los socios de la Jabonera propietarios de terrenos algodoneros» con el fin de «conseguir que la mayor parte de las acciones radiquen en (sus) manos».

Días después su optimismo parecía multiplicado. «Hay un verdadero entusiasmo relativo a la fundación (del) banco, y es seguro que la suscrición pasará en mucho los cinco millones de pesos», le transmitía a un viejo 
amigo. Tomás Mendirichaga y Hernández colaboraba desde Monterrey, donde en cuestión de horas había colocado medio millón. El 25 de abril quedó confirmada la suma de seis millones de pesos. Habían transcurrido menos de treinta días desde que hiciera llegar a su apreciado Luis Gurza «la lista posible de suscritores» ${ }^{54}$.

Entre éstos figuraban numerosos españoles, incluida la infaltable Sucesores de Hernández Hermanos (cuadro 6). Tomás Mendirichaga, Mariano Hernández y Leandro Urrutia integraron el primer Consejo de Administración. El Banco de la Laguna fue inaugurado en febrero de 1908 y no cesó de funcionar hasta la década de los cuarenta, cuando quedó fusionado a otra institución bancaria.

\section{CUADRO 6}

Españoles en el Banco de la Laguna (1907-1908)

\begin{tabular}{|c|c|c|}
\hline Nombre & Procedencia & Actividad \\
\hline Tomás Mendirichaga. & Monterrey & Comercio/industria \\
\hline Sucs. Hernández Hnos. . & Monterrey & Comercio/agricultura \\
\hline Ricardo Hdez. Mendirichaga ............. & Monterrey & Comercio \\
\hline Ulpiano Ruiz Lavín....... & La Laguna/Santander & Agricultura \\
\hline Rafael Arocena .................... & La Laguna & Agricultura \\
\hline Joaquín Serrano...... & La Laguna & Agricultura/industria \\
\hline Lendro Urrutia.................. & La Laguna & Agricultura \\
\hline José María Urrutia ............................ & La Laguna & Agricultura \\
\hline Andrés Medellín.............................. & La Laguna & Agricultura \\
\hline Federico Cobián .................................. & México DF & Comercio/agricultura \\
\hline
\end{tabular}

FUENTE: AB, Copiadores, 1906-1908.

\section{Por Chihuahua y Durango}

Mientras en la Laguna se extendían los cultivos de algodón y se asociaban los capitales norteños, en la interminable Chihuahua se afirmaban los Terrazas y su imperio. Fue en estos años cuando arribó el vasco Federico Sisniega. Había llegado a México en 1874, y a comienzos de los ochenta se hizo cargo de la sucursal Guanajuato del antiguo Banco Mercantil Mexi-

\footnotetext{
${ }^{54}$ Todas las referencias provienen del $\mathrm{AB}$, Copiadores y Correspondencia.
} 
cano. En 1887 y 1888 ocupó la gerencia de la sucursal Guadalajara del recién formado Banco Nacional de México. En 1888 se asentó en la ciudad de Chihuahua para dirigir la sucursal local del propio Banamex, de la que fue gerente hasta 1911.

Fue en este período cuando sus actividades se diversificaron: ganadería, agricultura, industria textil, industria harinera, transportes, minería. Sumó, además, una gran virtud: se casó con Amada Terrazas, hija del general-terrateniente, con la que procreó cinco hijos. Su incorporación a la familia Terrazas le abrió un mundo casi inagotable de oportunidades al emparentarse con Enrique C. Creel y Juan Terrazas. Una de sus hijas, más tarde, se casaría con Salvador Creel Terrazas, hijo del gran banquero chihuahuense.

Federico Sisniega completó su carrera empresarial con dos detalles: fue cónsul de España en Chihuahua entre 1900 y 1913 (cuando debió huir del país) e invirtió en la agricultura del algodón en la próspera comarca lagunera. En este último quehacer en realidad acompañó a su hermano Sinforiano, que residía en la ciudad de Durango. Sinforiano se había casado con Rosa Flores, hija del más famoso de los terratenientes duranguenses de mediados de siglo y uno de los principales promotores de la región lagunera: Juan Nepomuceno Flores. Un cuñado de Sinforiano - Juan Francisco Flores- se contaba entre los más encumbrados dirigentes políticos de Durango y fue - a la vez- influyente hombre de negocios.

El Sisniega de Durango y Juan Francisco Flores se asociaron entre 1888 y 1895 para cultivar algodón: arrendaron los ranchos «San Agustín» $\mathrm{y}$ «Santa Fe» (que integraban la famosa hacienda algodonera «La Concha», propiedad del coronel Carlos González). Al morir Juan Nepomuceno Flores sus hijos heredaron amplias extensiones de tierras en la parte duranguense de la Laguna. Sinforiano, como su hermano, fue representante consular de España, pero en la ciudad de Durango ${ }^{55}$.

\section{Españoles e industria en Monterrey}

\section{La industria pesada}

Fue en los años noventa cuando Monterrey se convirtió en la más dinámica urbe del norte de México. Nudo ferroviario de primer orden,

"Véanse las referencias en León (1992), Wasserman (1987), Cerutti (1985). 
sus grupos mercantiles volcaron a la producción industrial y minera gran parte de los bienes y recursos concentrados en décadas previas. Las demandas de un mercado nacional que se ampliaba y la cercanía relativa de uno de los escenarios fundamentales de la segunda revolución industrial - la franja atlántica de los Estados Unidos- lo justificaban y explican.

Aunque el inicial florecimiento fabril de Monterrey incluyó la producción liviana - como Sao Paulo, Medellín, Buenos Aires, Santiago de Chile o el valle de México-, su matiz particular resultó la instalación de la gran metalurgia básica. A comienzos de los noventa fueron montadas tres grandes plantas de fundición: la Nuevo Leon Smelting and Refining; la Compañía Minera, Fundidora y Afinadora Monterrey, S. A., y la estadounidense Gran Fundición Nacional Mexicana (que se llamaría luego American Smelting and Refining, Co.). Su objetivo central era abastecer la ávida demanda de metales industriales - plomo, sobre todo- del noreste estadounidense ${ }^{56}$.

En las dos primeras, sustentadas en capitales regionales, participaron empresarios de origen español. En la Nuevo Leon Smelting invirtieron Félix Mendirichaga y Pedro Maiz y Cía. La Minera, Fundidora y Afinadora tuvo entre sus accionistas al vasco Francisco Armendaiz y a miembros del clan Hernández-Mendirichaga. La experiencia empresarial adquirida, la asociación con otros capitales regionales y del exterior, las solicitudes del sistema ferroviario y la visible articulación del mercado interior llevaron a la puesta en marcha de un cuarto establecimiento: la Compañía Fundidora de Fierro y Acero de Monterrey, S. A., primera siderurgia integrada de América Latina que efectuó su colada inaugural en 1903 apoyada en una inversión de cinco millones de dólares.

El montaje de estas grandes plantas de metalurgia básica - productoras de bienes destinados al abastecimiento de la propia producción, dentro y fuera de las fronteras nacionales- perfiló y singularizó a Monterrey en el contexto latinoamericano de principios de siglo. Dentro de ese marco, Fundidora de Fierro y Acero representó un caso llamativo. Entre otras cosas -y desde el enfoque de este artículo-, por la fuerte participación de capitalistas de origen español que intervinieron en su fundación y desarrollo.

El mecanismo de la sociedad anónima permitió la reunión de capitales en un plazo relativamente corto y abrió las puertas a una muy significativa intervención de vascos, asturianos y algún santanderino. Ya entre sus cuatro promotores iniciales figuraba un vasco prominente, oriundo de Algorta: Antonio Basagoití, fundador del Banco Hispanoamericano y accionista influ-

${ }^{56}$ Cerutti (1992b), cap. 6. 
yente del Banco Nacional de México. Una revisión de la lista de accionistas (cuadro 7) permite verificar la notoria intervención de empresarios con raíces peninsulares. Si se contabilizan las acciones que adquirió Valentín Rivero y Gajá (hijo del asturiano Valentín Rivero), el total de la participación hispana sumó 28.500 acciones, es decir, el 28,5 por 100 , lo que suponía una suma cercana al millón y medio de dólares. La intervención de Basagoití, es obvio, fue de gran calibre, sólo superada por la familia Milmo (24.444 acciones). Basagoití integró también la primera lista de directores propietarios. En la de suplentes estaban otro vasco, Joaquín Maiz, y el inesquivable Tomás Mendirichaga. Aunque no figuró entre los fundadores, el también asturiano Adolfo Prieto y Álvarez estuvo destinado a cumplir un papel protagónico en Fundidora, a la que dirigió desde 1907 hasta su muerte (enero de 1945) ${ }^{57}$.

\section{CUADRO 7}

Accionistas de raíces hispanas en Fundidora (1990)

\begin{tabular}{|c|c|}
\hline Nombre & Acciones \\
\hline Antonio Basagoití.. & 21.500 \\
\hline 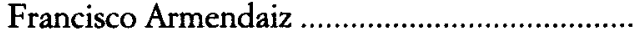 & 1.000 \\
\hline Francisco Armendaiz e Hijo ..................................... & 50 \\
\hline Agustín Maiz... & 1.000 \\
\hline 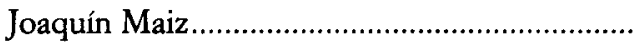 & 50 \\
\hline 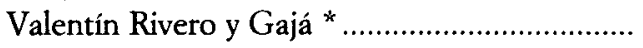 & 1.200 \\
\hline 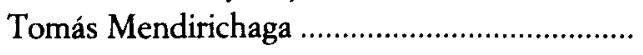 & 3.000 \\
\hline 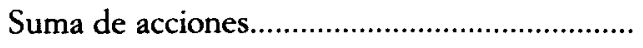 & 28.500 \\
\hline 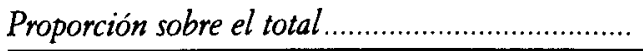 & $28,5 \%$ \\
\hline
\end{tabular}

* Hijo mayor del asturiano Valentín Rivero y Álvarez Jove.

Fuentes: AGENL, protocolo de Tomás C. Pacheco, 5 de mayo de 1900; Archivo de Fundidora de Fierro y Acero de Monterrey (AFFA, Monterrey), Actas.

57 Nacido en Sama de Grado, Prieto entró a México por Veracruz y desde el principio se vinculó a Antonio Basagoití y su casa mercantil. Cuando Basagoití se marcho a España traspasó su ya acreditada firma a Joaquín Ibáñez y al propio Prieto, quienes fundaron la casa Ibáñez y Prieto Sucesores de A. Basagoiti. La razón social pasó a llamarse luego Ibánez y Prieto, que subsistió hasta 1914. En ese momento esta firma mercantil era propietaria de más del 50 por 100 de las acciones de Fundidora, a la cual Prieto arribó por influencia directa de Basagoití y de un grupo de accionistas de la ciudad de México. Referencias documentales y bibliográficas en Cerutti (1995), pp. 157-162. 
Los españoles en el despegue regiomontano

Una rápida revisión de las sociedades fundadas entre 1890 y 1910 por el empresariado con asiento en Monterrey permite comprobar - -junto a la muy marcada diversificación de las inversiones, su ramificación regional y las múltiples redes entre los dueños del capital - la estratégica participación de los españoles.

\section{CUADRO 8}

Monterrey: inversiones de españoles y sucesores (1890-1905)

(composición por sectores)

\begin{tabular}{|c|c|c|}
\hline Sectores * & Número sociedades & Porcentaje del total \\
\hline 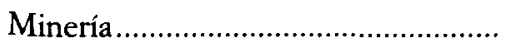 & 77 & 66,9 \\
\hline 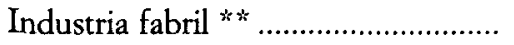 & 18 & 15,6 \\
\hline 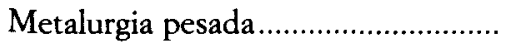 & 3 & 2,6 \\
\hline 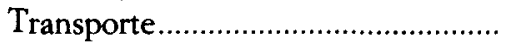 & 6 & 5,2 \\
\hline 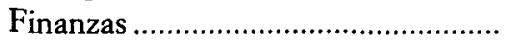 & 5 & 4,3 \\
\hline 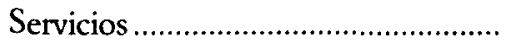 & 5 & 4,3 \\
\hline 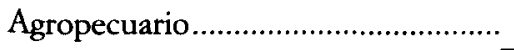 & 1 & 0,8 \\
\hline Total... & 115 & 100,0 \\
\hline
\end{tabular}

* No incluye comercio.

** No incluye metalurgia pesada.

FUENTE: AGENL, libros de notarios, 1890-1905.

La fusion de capitales dispersos en la geografía norteña facilitó la canalización de múltiples inversiones con riesgos mínimos para cada empresario. En un movimiento cotejable a lo que sucedió en el País Vasco desde 1880, el auge posterior a 1890 condujo a la fundación de centenares de empresas mineras, agrícolas, pecuarias, bancarias, de servicios y fabriles. Los apellidos Zambrano, Ferrara, Milmo, Madero, Belden, Muguerza, Garza, González Treviño y Sada, junto a nuestros conocidos Armendaiz, Hernández, Mendirichaga, Maiz y Rivero aparecieron eslabonados a múltiples proyectos.

Fracción sustancial del grupo empresarial de Monterrey y sus aledaños, los antiguos comerciantes y agentes de crédito de origen hispano $\multimap$ sus descendientes- estuvieron entre los principales diseñadores de tan fundamental andamio para la construcción del capitalismo en el norte mexi- 
cano. La proporción dentro de cada sector —entre 1890 y 1905 - se sintetiza en el cuadro 8.

Un caso sobresaliente fue el vasco Armendaiz. Entre 1890 y 1900 se contabilizó su participación en 56 compañías, con la composición ${ }^{58}$ que refleja el cuadro 9.

\section{CUADRO 9}

Composición de las inversiones de Armendaiz (1890-1900)

\begin{tabular}{|c|c|c|}
\hline Sectores & Número empresas & Porcentaje del total \\
\hline 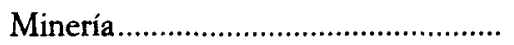 & 37 & 66,0 \\
\hline 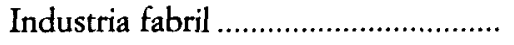 & 7 & 12,5 \\
\hline 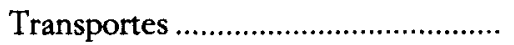 & 4 & 7,1 \\
\hline 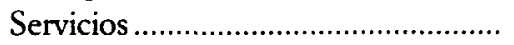 & 3 & 5,3 \\
\hline 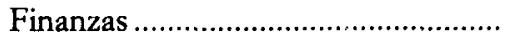 & 2 & 3,5 \\
\hline 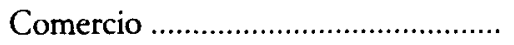 & 2 & 3,5 \\
\hline 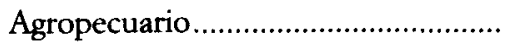 & 1 & 1,7 \\
\hline
\end{tabular}

FUENTE: AGENL, libro de notarios, 1890-1905.

Antes de finalizar es oportuno indicar la consistente participación que en el sector financiero y bancario tuvieron los inmigrantes indagados. El caso más llamativo fue la casa Hernández. Al fundarse el Banco Mercantil de Monterrey (en 1899) adquirió el mayor paquete de acciones: 6.523 . Surgida, hay que recordar, a mediados del Xxx, la casa Hernández era a finales de siglo el segundo gran accionista del muy sólido Banco Minero de Chihuahua, que dirigía el encumbrado Enrique C. Creel (sólo John Brittingham contaba con más acciones en esa firma financiera). Los Hernández participaron en la fundación del Banco de Coahuila (1897) y -como ya se vio- en la creación del Banco de la Laguna. Francisco Armendaiz,

${ }^{58}$ Esta información - junto a la recogida en Puebla, Veracruz, el valle de México, Michoacán, La Laguna y Chihuahua - pone en duda la generalización que en trabajos previos se había adjudicado al comportamiento de los españoles en México: sólo se dedicaban - se ha repetido- al comercio (minorista), a administrar tiendas de raya o eran grandes propietarios de tierras. Aunque esta conclusión no es completamente incorrecta, investigaciones recientes dejan en evidencia que el comercio y la propiedad o administración de la tierra estuvieron enmarcadas —en vísperas de la Revolución- por actividades tan modernizantes y de riesgo como la industria, la minería y la banca. Cerutti (1995).

59 Tomás Mendirichaga, por su lado, suscribió 600, y Mariano Hernández y Mendirichaga, 50. AGENL, protocolo de Francisco Pérez, noviembre de 1899, fs. 186-214. 
por su lado, se contó en 1892 entre los gestores del Banco de Nuevo León, institución que tenía como soporte principal a la familia Madero ${ }^{60}$. Desde dos años antes, además, compartía con Valentín Rivero la conducción de la sucursal regiomontana del Banco Nacional de México.

\section{COMENTARIOS FINALES}

1. Alguien que hubiese recorrido los verdísimos y húmedos paisajes que se acuestan sobre el mar Cantábrico — desde Asturias hasta San Sebastián- podría preguntarse: ¿Cómo lograron adaptarse a los ocres y rudos desiertos del norte mexicano, un siglo y medio atrás, los españoles nacidos en el septentrión peninsular? ¿Cómo hicieron, por ejemplo, los hermanos Maiz o Francisco Armendaiz para reemplazar los arroyos del monte vasco por ese escenario tórrido y hosco que rodeaba al Bravo, envuelto en guerras interminables y siempre acechado por apaches y comanches? ¿Qué fue lo que arrastró a Valentín Rivero hasta la lejanísima Monterrey, a Santiago Lavín hacia la aún inexistente comarca lagunera, a José San Román hasta la polvorienta Matamoros? Quizá lo decisivo fue que estos inmigrantes se lanzaron a edificar en el país anfitrión, con fervor, su anhelada fortuna indiana. Y no pocos lo lograron.

2. No sólo se enriquecieron. El norte de México —una auténtica economía de frontera - permitió poner en evidencia la capacidad de gestión empresarial que desenvolvieron muchos de estos emigrados, capacidad que rebasó con amplitud el quehacer mercantil (que no era minúsculo, por cierto) y se desplazó hacia la propiedad de la tierra, la agricultura, la agroindustria, la industria fabril, la minería y las finanzas.

3. ¿Qué había en el norte mexicano? Una muy variada gama de oportunidades. Desde 1848 - tras la definición del río Bravo como nueva línea limítrofe- estos áridos territorios se convirtieron en prolongación económico/geográfica del más dinámico mercado nacional surgido en el mundo atlántico: los Estados Unidos. Si tal posibilidad se manifestó en un primer momento con el naciente estado de Texas, desde mediados de los setenta -y gracias al mismo Texas- el norte mexicano se comenzó a articular con el este y el medio oeste del país vecino, uno de los escenarios fundamentales de la segunda revolución industrial.

4. Las oportunidades que brindó la flamante línea fronteriza a la vida comercial fueron complementadas a partir de los ochenta con un rico raci-

${ }^{60}$ AGENL, libros de notarios, León (1992), Cerutti (1992b). 
mo de actividades: minería, agricultura especializada, transportes, una renovada ganadería, banca, servicios urbanos, explotaciones forestales, industria fabril (liviana y pesada). El ferrocarril conectaba los desiertos mexicanos con las demandas estadounidense y articulaba un mercado interno redimensionado por una firme especialización regional. ¿Por qué no iban a aprovechar estas oportunidades los emigrados del otro norte, asturianos, vascos, santanderinos?

5. Como muchos de los españoles analizados tuvieron un estrecho contacto con el comercio y con el préstamo, su estudio ha permitido comprobar de paso la importancia del capital mercantil en los años de transición o de reconstrucción previos a 1885, cuando realmente empezó a entrar en México el capital extranjero. Los capitales manejados por los españoles habían sido acumulados en los propios espacios regionales en que actuaban y de ninguna manera puede inferirse que fueron importados. Lo curioso es que esto no sólo era realizado por españoles: la investigación reciente ha verificado casos análogos con alemanes, franceses y británicos. La trayectoria del joven Brittingham - señalado aquí- es una muestra más, aunque referida a un estadounidense.

6. Este norte centro/oriental -como también Puebla, Veracruz, Michoacán o el muy poblado espacio central que rodeaba la ciudad de México- nos aproxima a otra conclusión: los españoles habrían configurado uno de los grupos de propietarios/empresarios de raíces extranjeras más poderoso del México prerrevolucionario. Se trata de una hipótesis que, con demasiada insistencia, insinúan las investigaciones regionales. $Y$ que pondría de cabeza, es notorio, la descontada omnipresencia del empresariado anglosajón: la literatura socioeconómica más general puede haber confundido la dimensión cuantitativa de los capitales provenientes de los Estados Unidos y de Europa -macroinversiones en ferrocarriles y minería realizadas después de 1885 - con el proceso formativo del empresariado que se manifestó en diferentes regiones de México durante y tras los tumultuosos años de las reformas liberales. En este específico proceso los españoles desempeñaron un papel muy significativo.

\section{ARCHIVOS CONSULTADOS}

Archivo Histórico Papeles de Familia (AHPF, Torreón). Archivo de Notarías del Estado de Durango (ANED, Durango). Archivo General del Estado de Coahuila (AGEC, Saltillo). Archivo Municipal de Saltillo (AMS, Saltillo). 
Archivo General del Estado de Nuevo León (AGENL, Monterrey).

Archivo Brittingham (AB, Monterrey).

Archivo de la Compañía Fundidora de Fierro y Acero de Monterrey (AFFA, Monterrey).

Archivo Histórico de Banamex (ABMX, México DF).

Barker Texas History Center (BTHC, Austin, Texas).

Archivo Histórico Provincial de Vizcaya (AHPV, Bilbao).

\section{BIBLIOGRAFÍA}

CerutTI, Mario (1992a), «Comerciantes y generalización del crédito laico en México (1860-1910). Experiencias regionales», en Anuario del IEHS (Tandil, Argentina), 7.

- (1992b), Burguesía, capitales e industria en el norte de México. Monterrey y su ámbito regional (1850-1910), México, Alianza Editorial/Universidad Autónoma de Nuevo León.

- (1994a), «Entre el río Bravo y La Habana. Los comerciantes en la guerra de Secesión (1861-1865)», en Clara LIDA (comp.), Una inmigración privilegiada. Comerciantes, empresarios y profesionales españoles en México en los siglos XIX $y x x$, Madrid, Alianza Editorial.

- (1994b), «Empresarios y sociedades empresariales en el norte de México (1870-1920)», en Revista de Historia Industrial, 6.

- (1995), Empresarios españoles y sociedad capitalista en México (1840-1920), Colombres, Archivo de Indianos/Ministerio de Asuntos Sociales.

- (1996a), «Estudios regionales e historia empresarial en México (1840-1920). Una revisión a lo producido desde 1975», en Carlos DÁvILA L. DE Guevara (comp.), Empresa e bistoria en América Latina. Un balance bistoriográfico, Bogotá, Tercer Mundo Editores/Colciencias.

- (1996b), «El norte de México, Texas y el comercio atlántico (1850-1875). José San Román: guerras, algodón y plata en la frontera del Bravo», en IberoAmerikaniscbes Arcbiv, vol. 22, 1-2 de enero.

- (1997), «La Compañía Industrial Jabonera de la Laguna. Comerciantes, agricultores e industria en el norte de México (1880-1925)», en Carlos MARICHAL y Mario CerutTr (comps.), Historia de las grandes empresas en México (1850-1930), México, Fondo de Cultura Económica/Universidad Autónoma de Nuevo León.

- CoRTÉs CONDE, Roberto (1988), «Migración, cambio agrícola y políticas de protección. El caso argentino», en Nicolás SÁnCHEZ-AlbORNOZ (comp.), Españoles bacia América. La emigración en masa, 1880-1930, Madrid, Alianza Editorial.

Cowling, Annie (1926), «The Civil War Trade of the lower Rio Grande Valley», tesis de maestría, Universidad de Texas.

Delaney, Robert (1955), «Matamors, Port of Texas during the Civil War», en Soutbwestern Historical Quarterly, vol. LVIII, 4 de abril.

DiAmOND, William (1940), «Imports of the Confederate Government from Europe and Mexico», en The Journal of Southern History, vol. VI, 4 de noviembre. 
Flores TORRES, Óscar (1994), Revolución mexicana y diplomacia española. Contrarrevolución y oligarquia bispana en México, 1909-1920, México, Instituto Nacional de Estudios Históricos de la Revolución Mexicana.

- (1997), «Revolución, diplomacia y grupos económicos hispanos en el norte de México (1910-1917)», en Españoles en el norte de México. Propietarios, empresarios y diplomacia (1850-1920), Monterrey, Universidad Autónoma de Nuevo León/Universidad de Monterrey.

Gómez MendozA, Antonio (1982), Ferrocarriles y cambio económico en España (1855-1913), Madrid, Alianza Editorial.

Graf, Le Roy (1942), «The Economic History of the lowr Rio Grande Valley», tesis doctoral, Universidad de Harvard.

Hernandez, Carlos (1903), Durango Gráfico, Durango, Talleres de J. S. Rocha. HERNÁNDEZ MENDIRICHAGA, M. (1945), Notas sobre la actuación de la sociedad mercantil sucesores de Hermández Hermanos. Monterrey (1855-1943), Monterrey.

IRBY, James Arthut (1969), «Line of the Rio Grande: War and Trade on the Confederate Frontier, 1861-1865», tesis doctoral, Universidad de Georgia.

LEÓN, Ricardo (1992), «La banca chihuahuense durante el porfiriato», en Siglo XIX. Cuadernos de Historia (Monterrey), 2 de febrero.

LIDA, Clara (1994, comp.), Una inmigración privilegiada. Comerciantes, empresarios y profesionales españoles en México en los siglos XIX y XX, Madrid, Alianza Editorial.

MaChUCA MaCías, Pablo (1991), Ensayo sobre la fundación y desarrollo de la ciudad de Gómez Palacio, Gómez Palacio, Legislatura de Durango.

Maluquer de MOTES, Jordi (1992), Nación e inmigración: los españoles en Cuba (siglos XIX y XX), Colombres, Fundación Archivo de Indianos/Júcar.

MAYER, Arthur James (1976), «San Antonio, Frontier Entrepot», tesis doctoral, Universidad de Texas.

MeYERS, William K. (1997), Forja del progreso, crisol de la Revolución. Los orígenes de la revolución mexicana en la comarca lagunera, 1880-1911, Saltillo, Instituto Nacional de Estudios Históricos de la Revolución Mexicana/Universidad Iberoamericana/Instituto Estatal de Documentación de Coahuila.

OwsLey, Frank Lawrence (1931), King Cotton Diplomacy. Foreign Relations of the Confederate States of America, Chicago, The University of Chicago Press.

Plana Manuel (1996), El reino del algodón en México. La estructura agraria de la Laguna, 1855-1910, Monterrey, Universidad Autónoma de Nuevo León/ Universidad Iberamericana/Centro de Estudios Sociales y Humanísticos.

Reed, S. G. (1981), A History of the Texas Railnoads, Nueva York, Arno Press. SÁNCHEZ AlONSO, Blanca (1988), «La emigración española a la Argentina, 1880-1930», en Españoles bacia América, citado.

- (1992), La inmigración española en Argentina. Siglos xix y xx, Colombres, Fundación Archivo de Indianos/Júcar.

Saravia, Emiliano G. (1909), Historia de la comarca de la Laguna y del río Nazas, México, Sindicato de Ribereños Inferiores del río Nazas.

SEGRETO, Luciano (1994), «De la historia económica a la historia de la empresa: la marcha del debate en España», en SEgreto y G. NúNEz (comps.), Introducción a la bistoria económica de la empresa en España, Madrid, Abacus.

TyLER, Ronnie C. (1973), Santiago Vidaurri and the Southern Confederacy, Austin, Texas Historical Association. 
VARGAS-LoBSINGER, María (1984), La bacienda de «La Concha». Una empresa algodonera de la Laguna, 1883-1917, México, Universidad Nacional Autónoma de México.

Vera Estañol, Jorge (1910), Compañia Agrícola, Industrial, Colonizadora, Limitada del Tlabualilo vs. Gobierno Federal, México, Imprenta y Fototipia de la Secretaría de Fomento.

WASERMAN, Mark (1987), Capitalistas, caciques y revolución. La familia Terrazas de Chibuabua, 1854-1911, México, Enlace-Grijalbo.

Zuleta, María Cecilia (1996), «Y la bola empezó. El algodón: botín de muchos», en Boletín INERHM, 12 de julio-septiembre. 